\title{
Reconstructing the effects of hurricanes over 155 years on the structure and diversity of trees in two tropical montane rainforests in Jamaica
} McLaren, Kurt; Luke, Denneko; Tanner, Edmund ; Bellingham, Peter J; Healey, John

\section{Agricultural and Forest Meteorology}

DOI:

10.1016/j.agrformet.2019.107621

Published: 15/10/2019

Peer reviewed version

Cyswllt i'r cyhoeddiad / Link to publication

Dyfyniad o'r fersiwn a gyhoeddwyd / Citation for published version (APA):

McLaren, K., Luke, D., Tanner, E., Bellingham, P. J., \& Healey, J. (2019). Reconstructing the effects of hurricanes over 155 years on the structure and diversity of trees in two tropical montane rainforests in Jamaica. Agricultural and Forest Meteorology, 276-277.

https://doi.org/10.1016/j.agrformet.2019.107621

\footnotetext{
Hawliau Cyffredinol / General rights

Copyright and moral rights for the publications made accessible in the public portal are retained by the authors and/or other copyright owners and it is a condition of accessing publications that users recognise and abide by the legal requirements associated with these rights. study or research

- Users may download and print one copy of any publication from the public portal for the purpose of private

- You may not further distribute the material or use it for any profit-making activity or commercial gain

- You may freely distribute the URL identifying the publication in the public portal?
}

Take down policy

If you believe that this document breaches copyright please contact us providing details, and we will remove access to the work immediately and investigate your claim. 
1 Reconstructing the effects of hurricanes over 155 years on the structure and diversity of

2 trees in two tropical montane rain forests in Jamaica

3

4 Kurt McLaren $^{\mathrm{a}^{*}}$, Denneko Luke ${ }^{\mathrm{a}}$, Edmund Tanner ${ }^{\mathrm{b}}$, Peter J Bellingham ${ }^{\mathrm{c}}$ and John R Healey ${ }^{\mathrm{d}}$

5

$6 \quad{ }^{a}$ Department of Life Sciences, University of the West Indies, Mona, Kingston 7, Jamaica

$7 \quad{ }^{\mathrm{b}}$ Department of Plant Sciences, University of Cambridge, Downing Street, Cambridge CB2

$8 \quad 3 E A$, United Kingdom.

$9 \quad{ }^{\mathrm{c}}$ Manaaki Whenua - Landcare Research, P. O. Box 69040, Lincoln 7640, New Zealand

$10{ }^{\mathrm{d}}$ School of Natural Sciences, Bangor University, Bangor, Gwynedd, LL57 2UW, United

11 Kingdom

12

13 *Corresponding author: Tel: +18769272753; Email address: kurt.mclaren@uwimona.edu.jm

14

15

16

17

18

19

20

21

22

23 


\section{Abstract}

25 The effects of the spatiotemporal ( $>100$ years) range of hurricane disturbance intensity on tree

26 diversity and density patterns are largely unknown, because data on past stand or landscape scale

27 hurricane impacts are sometimes unavailable. We therefore reconstructed and mapped topographic exposure (a proxy to disturbance) to twelve category $2-4$ hurricanes that affected the

29 rain forests of the Blue Mountains (BM) and the John Crow Mountains (JCM) in Jamaica, over 155 years. Maps of average topographic exposure and the spatial outputs from a pixel-based

31 polynomial regression of the cardinal directions of the tracks of past hurricanes (predictor) and

32 past exposure (response) were then used to represent the aggregate spatiotemporal range of exposure. Next, we used data collected over the period 1974-2009 from 35, 10 x10 m nested

34 subplots and 1991-2004 from 16, $200 \mathrm{~m}^{2}$ circular plots for the BM and 2006-2012 from 45, $25 \mathrm{x}$ $25 \mathrm{~m}$ plots for the JCM, and Bayesian spatiotemporal, Integrated Nested Laplace Approximation (INLA) models to determine whether stand-level $\left(\approx 1 \mathrm{~km}^{2}\right)$ tree Shannon diversity and density

37 patterns were primarily influenced by exposure to a single hurricane, the most severe hurricane or to multiple hurricanes and the duration of hurricane effects on Shannon diversity and tree

39 density. In the BM, long-term diversity peaked at locations with intermediate values of average exposure for six hurricanes (five of which made landfall over the period 1903-1988). Short-term

41 diversity peaked at locations that experienced significantly higher exposure situated to the south

42 or north of the hurricane's track when the tracks were to the north or south of the island,

43 respectively. Short-term density peaked at locations that were always highly exposed. Moreover,

44 the influence of the most severe hurricane on diversity can last up to 101 years and the influence 45 of the most recent hurricane (Gilbert) on diversity became evident after $16-21$ years. The JCM 46 was more susceptible to hurricanes and this diminished the influence of past hurricanes. 
47 Consequently, density peaked at sites with the highest average exposure to the four most recent 48 hurricanes (1988-2007), only one of which made landfall. If historical hurricane disturbance data 49 are unavailable, reconstructed exposure maps can be used to provide valuable insights into the 50 effects of past hurricanes on stand-level tree diversity and density patterns.

52 Keywords: Bayesian; Integrated Nested Laplace Approximation; intermediate disturbance 53 hypothesis; topographic exposure; spatiotemporal models; cyclone; forest structure.

\section{Introduction}

57 Tropical forests on most islands worldwide are subject to repeated effects of tropical cyclones 58 (also referred to regionally as hurricanes and typhoons) (Boose et al. 2004; Bellingham 2008). 59 As a hurricane moves across a forested landscape, meteorological, biological and topographic 60 factors interact to create complex patterns of damage at different spatial scales (Xi et al. 2008).

61 At the ecosystem level (e.g. forest stands), hurricanes cause leaf stripping, branch breakage or 62 loss, snapping of tree crowns and uprooting, and individual and multi-tree blow downs (Boose et 63 al. 1994; Boose et al. 2004; Rossi et al. 2017). At landscape scales, hurricane impacts are 64 generally heterogeneous and, as such, there are usually gradients of damage and mortality across 65 the landscape (Gannon and Martin 2014). The heterogeneity of forest damage is determined by 66 wind velocity gradients that result from the intensity, size and proximity of a hurricane, and their 67 interaction with the abiotic and biotic attributes of a landscape (Zimmerman et al. 1994;

68 Everham and Brokaw 1996; Boose et al. 2004). The abiotic attributes of a landscape that 69 contribute to the heterogeneity of forest disturbance include soils and geomorphology, both of 
70 which affect windthrow vulnerability and landslide distribution and local topography which

71 determines differences in site exposure (Bellingham, 1991; Scatena and Larsen, 1991;

72 Zimmerman et al. 1994; Everham and Brokaw 1996; Boose et al. 1994; Gannon and Martin

73 2014). Biotic features such as forest type, species composition, structural attributes and the

74 characteristics of tree species (stem size [height and diameter], architecture and wood density as

75 examples) influence the susceptibility and response of trees and forest stands to wind damage,

76 and contribute to the heterogeneity of forest disturbance (Boose et al. 1994; Zimmerman et al.

77 1994; Everham and Brokaw 1996; Tanner and Bellingham 2006; McGroddy et al. 2013; Gannon

78 and Martin 2014).

79

80 The degree of structural change, species composition, and the method and rates of recovery

81 within forested stands across landscapes are affected by the spatial patterns of hurricane

82 disturbance (Runkle, 1985). Recovery of the forest canopy following a hurricane is quite rapid $(<$

8310 years) and normally occurs through tree releafing, sprouting, or recruitment of fast-growing

84 species (Boose et al. 2004). However, depending on the severity of hurricane disturbance, there

85 may be major structural changes, such as a significant reduction in biomass (Weaver 2002;

86 Heartsill Scalley 2017), wood volume, basal area, and canopy height (Luke et al. 2016a; Heartsill

87 Scalley 2017), which may take much longer to recover (> 10 years) (Weaver 2002; Heartsill

88 Scalley 2017). Additionally, over the long-term, trees may experience sudden or delayed

89 mortality and variation in growth rates related to the severity of hurricane damage, alterations in

90 regeneration pathways and successional trajectories, and increased species turnover (Weaver

91 2002; Boose et al. 2004; Tanner et al. 2014). Moreover, the heterogeneity of disturbance affects

92 spatiotemporal variability in environmental conditions and resources (Roxburgh et al. 2004). 
93 This facilitates the recruitment and establishment of species with diverse life history strategies in 94 the community (Tanner and Bellingham 2006; Luke et al. 2016a). Over time, these effects can 95 result in an increase in tree diversity and richness in forests (Denslow 1995; Vandermeer et al. 96 2000; Tanner and Bellingham 2006; Luke et al. 2016a; Heartsill Scalley 2017) and contribute 97 significantly to tree species coexistence and the maintenance of forest diversity (sensu: the 98 intermediate disturbance hypothesis [Connell 1978; Sheil 1999; Shea et al. 2004; Sheil and 99 Burslem 2013]). In addition, there is an increase in stem density in disturbed areas following a 100 hurricane (Tanner and Bellingham 2006) as a lower density of large trees is replaced by more 101 small trees (Denslow 1995). This effect on stem density lasts for many years, even after the 102 canopy has closed (Denslow 1995; Tanner and Bellingham 2006).

104 Forest susceptibility to wind damage is also influenced by previous hurricanes, as the impact of a 105 single hurricane event is not independent of past hurricanes (Webb 1958; Boose et al. 2004; 106 Hogan et al. 2018; Ibanez et al. 2019). A total of 152 hurricanes struck the islands of the Greater 107 Antilles, located in the northern Caribbean, between 1851 and 2009 (Gannon and Martin 2014). 108 The hurricane return interval for affected forest sites in the region is on average10 years, 109 although the most that any one site (the far west of Cuba) was struck was 34 times (with a 4.6 110 year hurricane return interval) (Gannon and Martin 2014). As such, trees that live for over 100 111 years in these forests are likely to be affected by many hurricanes during their lifespan (Weaver 112 1986). Therefore, the long-term impact of hurricanes on forest stands can only be understood on 113 a scale of decades to centuries (Boose et al. 1994). Yet, our understanding of hurricane damage, 114 and the mechanisms of short- and long-term recovery at forest sites in the Caribbean, is largely 115 based on stand-level assessments, conducted before and/or after a single hurricane event in 
116 decadal timescales. Meteorological models using data such as historical hurricane track, size,

117 wind speed and wind direction have been used to reconstruct the spatial patterns of disturbance,

118 over different periods (3-158 years) and at various scales (landscape and regional) (e.g. Boose et

119 al. 1994, 2004; Gannon and Martin 2014; Batke et al. 2014; Luke et al. 2016a). However, these

120 data are unavailable for most sites or they have been largely used to explain stand- or landscape-

121 level disturbance patterns and are not often used to explain stand-level fluctuations in tree

122 diversity and density. As a result, the cumulative effects of long-term ( $>100$ year) hurricane

123 disturbance intensity on forest community responses, such as dynamics and diversity patterns, is

124 less understood. Moreover, the number of high intensity cyhclones is predicted to increase due to

125 the effects of global climate change (Elsner et al. 2008; Bender et al. 2010; Knutson et al. 2010).

126 As a result, forest stands across the Caribbean and in other regions are beginning to become

127 increasingly affected by multiple high-intensity hurricanes (Luke et al. 2016a; Lin et al. 2017,

128 Uriarte et al. 2019). These hurricanes could accelerate structural and compositional changes,

129 particularly at sites that are more exposed to recent and previous hurricane events (Luke et al.

130 2016a). There is a need to increase our understanding of the impacts of the historical and

131 contemporary range of hurricane disturbance intensity, over space and time, on community

132 dynamics and diversity patterns (Boose et al. 1994; Gannon and Martin 2014; Batke et al. 2014).

134 Elucidating the effects of past hurricanes on forest stands will require an integrative approach

135 that combines stand-level $\left(\approx 1 \mathrm{~km}^{2}\right)$ observations with past landscape level $\left(\approx 10 \mathrm{~km}^{2}\right)$ hurricane

136 disturbance intensity data (e.g. Xi et al. 2008; Luke et al. 2016a). However, there is usually little

137 or no data available on past stand or landscape scale hurricane impacts. It is now possible to

138 generate historical and contemporary landscape scale data on hurricane impacts, due to an 
139 increase in the processing power of personal computers and the advent and availability of 140 Geographic Information System (GIS) software, spatial and geographic data and detailed 141 weather data. In addition, the emergence of the interdisciplinary field of geomorphometry, which

142 is concerned with the extraction or quantification of topographic parameters from digital 143 elevation models (DEMs: a digital representation of the terrain or land surface) in a GIS software 144 environment, has been instrumental (Pike et al. 2008; Batke et al. 2014). Topographic exposure 145 is a geomorphometric feature that characterises a site based on the degree of protection it 146 receives from the surrounding landscape and it is the main landscape feature that has been 147 quantified, mapped and used as a proxy for past wind or hurricane disturbance intensity (Ruel et 148 al. 2002; Mikita and Klimánek 2010; Batke et al. 2014; Luke et al. 2016a). Topographic 149 exposure maps have been generated for single and multiple hurricanes (Boose et al. 1994, 2004; 150 Luke et al. 2016a), and average exposure has been calculated based on multiple wind directions 151 (Mikita and Klimánek 2010) and wind inflection angles (Batke et al. 2014), which are used to 152 estimate the wind shadow (Boose et al. 1994). They have also been used to reconstruct $>100$ 153 years of hurricane disturbance regimes (Boose et al. 1994, 2004). Additionally, data from 154 exposure maps have been extracted and used to determine the cumulative effects of disturbances 155 from three hurricanes on structural changes and diversity at the stand-level (Luke et al. 2016a).

156 However, reconstructed hurricane exposure maps representing $>100$ years of hurricane 157 disturbance have never previously been used to determine the cumulative effects of the 158 spatiotemporal range of hurricane disturbances on forest structure and diversity at the stand159 level. 
161 In this study, we therefore sought to determine the cumulated effects of the spatiotemporal (>

162100 years) range of hurricane disturbances on stand-level spatiotemporal patterns of tree

163 diversity and density. To enable this, we reconstructed topographic exposure maps of hurricanes

164 that affected two adjacent montane sites with a similar disturbance history, the Blue Mountains

165 (BM) and the John Crow Mountains (JCM), in Jamaica, over 155 years (1852-2007). Two

166 methods of aggregating or summarizing the spatiotemporal range or pattern of past hurricane

167 exposure at the landscape scale $\left(\approx 10 \mathrm{~km}^{2}\right)$ were then evaluated. Luke et al. (2016a) summarized

168 the spatiotemporal range of exposure in the JCM by averaging exposure values extracted from

169 exposure maps for three hurricanes. However, the spatial pattern of exposure or disturbance is

170 also influenced by the distance and the angle/ cardinal direction of the hurricane's eye from and

171 relative to an island or other landmass (Luke et al. 2016a; Boose et al. 1994, 2004). Therefore,

172 we aggregated the spatial and temporal ranges of hurricane exposure by averaging the exposure

173 maps and by modelling the relationship between exposure and the distance or cardinal direction

174 of the tracks of the eye of each hurricanes from or relative to the study sites, and representing

175 these relationships spatially. Data from these maps were then extracted and used to determine

176 whether stand-level $\left(\approx 1 \mathrm{~km}^{2}\right)$ tree diversity and density spatiotemporal patterns over the periods

177 1974-2009 and 1990-2004 for the BM and 2006-2012 for the JCM, were primarily influenced

178 by exposure to a single hurricane, the most severe hurricane or multiple hurricanes and the

179 duration of hurricane effects on tree diversity and density patterns. We hypothesized that past

180 hurricanes will influence current patterns of diversity by maintaining the highest levels of tree

181 diversity at sites that historically experienced intermediate levels of disturbance. Species

182 coexistence and/or diversity are expected to peak under intermediate disturbance regimes

183 because longer-lived species will not persist if there is too much disturbance and pioneers will be 
184 competitively excluded if there is too little disturbance (Connell 1978; Sheil 1999; Shea et al.

185 2004; Sheil and Burslem 2013). We also hypothesized that tree density will be highest at sites

186 that historically experienced the highest levels of disturbance or exposure to hurricanes, on the

187 basis that stands which are frequently exposed to hurricane winds will have continually high

188 turnover rates and hence higher stem densities (Denslow 1995).

189

190 Study sites

191 The study sites are forests located on two mountain ranges in Jamaica, the Blue Mountains (BM)

192 and John Crow Mountains (JCM)). Together these ranges comprise the Blue and John Crow

193 Mountains National Park (Figure 1). Data used in this study were measured in plots that were

194 established close to the Grand Ridge of the BM $\left(18^{\circ} 05^{\prime}-18^{\circ} 059^{\prime} \mathrm{N}, 76^{\circ} 38^{\prime}-76^{\circ} 40^{\prime} \mathrm{W}\right)$ at an

195 elevation of 1320-1920 $\mathrm{m}$ in an upper montane tropical forest (Tanner 1977; Tanner and

196 Bellingham, 2006). The data from the JCM were measured in plots established along an

197 altitudinal gradient (400-800 m) at two different sites $\left(18^{\circ} 3^{\prime} \mathrm{N}, 76^{\circ} 21^{\prime} 39.6^{\prime \prime} \mathrm{W}\right)$ (Figure 1).

198 The JCM have a maximum elevation of $1143 \mathrm{~m}$ asl and the plots were established in both lower

199 and upper montane tropical forests (Luke et al. 2016a). Both sites have been affected by

200 hurricanes and the resulting effects on the forests have been documented: Hurricane Gilbert

201 (1988) (Bellingham 1991; Bellingham et al. 1992; Bellingham and Tanner 2000; Tanner and

202 Bellingham 2006; Tanner et al. 2014) and Hurricanes Ivan (2004), Dennis (2005) and Dean

203 (2007) (Luke et al. 2016a,b).

204

205 Method and materials

206 Reconstructing hurricane topographic exposure vulnerability 
207 Exposure vulnerability (EV) is a unitless measure that can be used to link the disparity in

208 hurricane exposure to the responses of tree species and the forest ecosystem at sites where there

209 is hurricane disturbance (Luke et al. 2016a). The calculation of EV requires hurricane tracks, a

210 digital surface model (DSM), and information on wind direction and speed (Luke et al. 2016a).

211 EV maps for three hurricanes (Ivan (2004), Dennis (2005) and Dean (2007)) were generated by

212 Luke et al. (2016a) and were used in this present study. Wind speed and direction data that were

213 used to construct the three EV maps were obtained from processed ultra-high-resolution images

214 of circular hurricane wind bands. These were created from QuikSCAT scatterometer satellite

215 data that were processed using a Scatterometer Image Reconstruction (SIR) technique (Early and

216 Long 2001). The images included colour-coded information on wind speed (in knots) overlaid

217 with wind flags, which point in the direction from which the wind is blowing (see: Luke et al.

218 2016a). However, QuikSCAT Scatterometer images (available at:

219 http://www.scp.byu.edu/data/Quikscat/HRStorms.html) are only available for the period 1999-

2202009 for hurricanes that developed in the Atlantic Ocean and the Caribbean Sea. Therefore, in

221 the present study, we used a method modified from Luke et al. (2016a) to reconstruct EV maps

222 for hurricanes that preceded 1999 using information on wind speed and wind direction obtained

223 from proxy or surrogate images.

225 To reconstruct the EV maps of pre-1999 hurricanes, we first downloaded an ESRI point .shp file 226 of the tracks of all hurricanes recorded in the Caribbean from the National Oceanic and

227 Atmospheric Administration (NOAA), National Climatic Data Center website

228 (http://www.ncdc.noaa.gov/ibtracs/index.php?name=wmo-data) and the tracks were re-projected 229 to the Jamaican datum, JAD 2001. Tracks of hurricanes categorized as category 2, 3 and 4 using 
230 the Saffir-Simpson Hurricane Wind Scale (maximum wind speed $\geq 154 \mathrm{~km} \mathrm{hr}^{-1}$ at their eye as 231 they passed at their closest points to the coastline of Jamaica) during the period 1852 to 1988

232 (Table 1), with centers that passed within $0-160 \mathrm{~km}$ of the northern or southern coastline of 233 Jamaica, were then selected. A $160 \mathrm{~km}$ threshold was used because Hurricane Emily, which 234 passed $160 \mathrm{~km}$ from the south coast (in 2005), had minimal effect on the JCM forest, as the outer 235 bands that passed over the JCM had wind speeds $<65 \mathrm{~km} \mathrm{hr}^{-1}$ (Luke et al. 2016a). Next, where 236 possible, surrogate/proxy QuikSCAT images representing 'typical' category 2, 3 and 4 hurricanes 237 over water in the Caribbean were selected and downloaded as a .gif file format and rectified to 238 the Jamaican datum. These images included Hurricanes Michelle (November 3, 2001; wind 239 speed: $167 \mathrm{~km} \mathrm{hr}^{-1}$; location: $18^{\circ} \mathrm{N} 84^{\circ} \mathrm{W}$ ), Charley (August 12, 2004; wind speed: $148 \mathrm{~km} \mathrm{hr}^{-1}$; 240 location: $20^{\circ} \mathrm{N} 81^{\circ} \mathrm{W}$ ), Ivan (September 11, 2004; wind speed: $240 \mathrm{~km} \mathrm{hr}^{-1}$; location: $18^{\circ} \mathrm{N} 80^{\circ}$ 241 W), Jeanne (September 20, 2004; wind speed: $111 \mathrm{~km} \mathrm{hr}^{-1}$; location: $26^{\circ} \mathrm{N} 72^{\circ} \mathrm{W}$ ), Emily (July 242 15, 2005; wind speed: $213 \mathrm{~km} \mathrm{hr}^{-1}$; location: $15^{\circ} \mathrm{N} 23^{\circ} \mathrm{W}$ ), Dennis (July 7, 2005; wind speed:

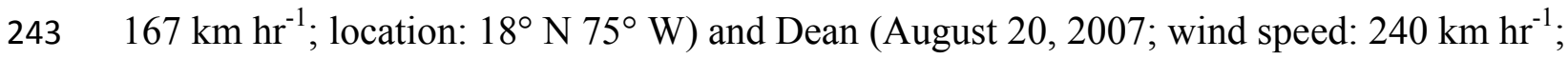
244 location: $\left.18^{\circ} \mathrm{N} 81^{\circ} \mathrm{W}\right)$. A list of hurricanes for which the EVs were reconstructed, and the proxy 245 hurricane(s) used to model the EV of each hurricane are presented in Table 1. The best proxy 246 image for Hurricane Gilbert was determined by comparing several proxy QuikSCAT images to a 247 rectified satellite image of Gilbert as it passed over Jamaica. Hurricane Ivan closely matched the 248 satellite image and was therefore used to model the final EV map of Hurricane Gilbert. The EV 249 of Hurricane Gilbert was also modelled using proxy hurricanes from the same Saffir-Simpson 250 Hurricane Wind Scale such as Hurricanes Emily and Dean, and the average of all three proxies 251 (Ivan, Emily and Dean). 
253 For each hurricane, the 'Georeferencing' function in ArcGIS was used to center the surrogate or 254 proxy hurricane images on the approximate location of the hurricane's eye, specifically on track 255 points found close to or over Jamaica. Wind flags found close to the JCM and BM were digitized 256 as polylines in ArcGIS. For wind speeds $\geq 64 \mathrm{~km} \mathrm{hr}^{-1}$, the upper value/range of the wind bands 257 that were likely to affect the BM and the JCM were used as estimates of wind speed. There were 258 no wind speed values for the wind bands closer to the track points (that is, for wind speeds $>93$ $259 \mathrm{~km} \mathrm{hr}^{-1}$ ). Average wind speed was estimated for these wind bands by averaging the wind speed 260 at the track point over which the image was centered and $93 \mathrm{~km} \mathrm{hr}^{-1}$, which was the maximum 261 wind speed of the wind category below the $>93 \mathrm{~km} \mathrm{hr}^{-1}$ category. The 'hillshade' feature in 262 ArcGIS was used with a digital surface model (DSM; $6.5 \mathrm{~m}$ resolution) of the eastern section of 263 Jamaica, to generate maps of topographic exposure to wind from various directions (following 264 Mikita and Klimánek 2010 and Batke et al. 2014). The hillshade feature requires the input of an 265 azimuth angle (wind direction) and an altitudinal angle (range $0^{-} 90^{\circ}$ ) (wind inflection angle). A

266 fixed wind inflection angle of $20^{\circ}$ that was used by Luke et al. (2016a), was used to create the 267 EV maps. Hillshade maps of exposure for each hurricane were generated by inputting the 268 following formula from Luke et al. (2016a) into the raster calculator in ArcGIS:

$$
\mathrm{EV}=\left(\sum_{i=1}^{n}\left({\text { wind } \operatorname{speed}_{i} * \text { hillshade map of exposure }}_{i}\right)\right) / n,
$$

270 where $i$ is one of several locations where the surrogate/proxy hurricane image(s) was (were) 271 centered and evaluated (e.g., location $(i)=1,2,3,4 \ldots$ ) and $n$ is the total number of locations 272 evaluated/hillshade maps created. 
275 Data from the upper montane rain forest of the BM are from the "Tanner's plots" established in 2761974 in four sites, within which are contiguous $10 \times 10 \mathrm{~m}$ plots (Col [0.09 ha], Mor [0.06 ha], 277 Mull [0.10 ha], and Slope [0.10 ha]; Tanner 1977). The plots were established within $300 \mathrm{~m}$ of 278 each other, at elevations 1580-1600 m (Figures 1 and 6) and covered a total area of 0.35 ha. 279 Although the plots are small in size and number, they sampled a representative area due to the 280 low tree species diversity in the BM. Specifically, 33 species that were sampled in the plots in 2812009 accounted for $93 \%$ and $95 \%$ of all the stems $(\geq 3 \mathrm{~cm} \mathrm{DBH})$ and basal area, respectively 282 (Chai et al. 2012). For a full description of the sites see Tanner (1977) and Tanner et al. (2014).

283 All stems $\geq 3 \mathrm{~cm}$ diameter at breast height (DBH, measured at $1.3 \mathrm{~m}$ aboveground) were 284 identified to species, scored as live or dead, and measured (DBH) in 1974, 1984, 1989, 1991, 285 1994, 2004, and 2009 (Tanner et al. 2014). When the plots were re-enumerated after Hurricane 286 Gilbert in 1989 and 1991, visible signs of hurricane damage and modes of recovery were 287 documented (i.e., percentage of all stems in the plots scored as defoliated, dead and resprouting; 288 Bellingham et al. 1995) and these data were used in this study.

290 More extensive data from the BM were derived from the "Bellingham's plots", specifically, 16

291 permanent $200 \mathrm{~m}^{2}$ circular plots covering a total area of 0.32 ha that were established in 1990 , 292 20-23 months after Hurricane Gilbert, along five, 500-m transects, $1 \mathrm{~km}$ apart (Bellingham 1991)

293 (Figures 1 and 7). The plots were established at elevations 1320-1920 m, and were located 294 orthogonal to the Grand Ridge of the BM at distances of 0, 250 and $500 \mathrm{~m}$ along each transect, at 295 the northernmost point, the top of the Ridge and the southernmost point, respectively 296 (Bellingham 1991) (Figures 1 and 7). All stems, living and dead, that were $\geq 3 \mathrm{~cm} \mathrm{DBH}$ were 297 measured and identified and the plots were re-enumerated in 1994 and 2004. Types of damage 
caused by Hurricane Gilbert and modes of recovery that were recorded included mortality,

uprooting, breakage, crown defoliation and resprouting (Bellingham 1991). Damage and

recovery (resprouting) were expressed as a percentage of all stems in the plots.

301

302

Table 1. Information on the hurricanes reconstructed in this study, including the date the first exposure vulnerability map for each hurricane was reconstructed, average wind speed or range of wind speeds at the eye, distance from the eye of the hurricanes to the closest point along the coastline of Jamaica, average cardinal direction (or angle) of the track of the eye of the hurricanes relative to the study sites (used in the Curve Fit and the calc polynomial regressions) and the proxy hurricanes used to reconstruct their exposure vulnerability.

\begin{tabular}{|c|c|c|c|c|c|}
\hline Hurricane & Date & $\begin{array}{c}\text { Wind speed } \\
\left(\mathrm{km} \mathrm{hr}^{-1}\right)\end{array}$ & $\begin{array}{c}\text { Distance } \\
(\mathbf{k m})\end{array}$ & $\begin{array}{c}\text { Angle } \\
\text { (degrees) }\end{array}$ & Proxy hurricane(s) \\
\hline 1852 (unnamed) & $06 / 10 / 1852$ & 167 & 73.5 & 199.08 & Jeanne \\
\hline 1880 (unnamed) & $06 / 08 / 1880$ & 148 & 71 & 195.81 & Jeanne \\
\hline 1903 (unnamed) & $11 / 08 / 1903$ & 195 & 0 & 279.17 & Jeanne \\
\hline 1912 (unnamed) & $17 / 11 / 1912$ & $93-185$ & 0 & 336.14 & Jeanne \\
\hline 1915 Galveston & $13 / 08 / 1915$ & 176 & 13.2 & 333.19 & Jeanne \\
\hline 1951 Charlie & $17 / 08 / 1951$ & $139-176$ & 0 & 202.08 & Michelle, Charley and Dennis \\
\hline 1964 Cleo & $25 / 08 / 1964$ & 232 & 113.7 & 40.71 & Michelle and Dennis \\
\hline 1980 Allen & $06 / 08 / 1980$ & 213 & 49 & 300.39 & Ivan, Emily and Dean \\
\hline 1988 Gilbert & $12 / 09 / 1988$ & $204-213$ & 0 & 215.75 & Ivan, Emily and Dean \\
\hline 2004 Ivan & $11 / 09 / 2004$ & $241-250$ & 40.3 & 203.44 & Ivan \\
\hline 2005 Dennis & $07 / 07 / 2005$ & 185 & 45.9 & 40.82 & Dennis \\
\hline 2007 Dean & $20 / 08 / 2007$ & 231 & 40.9 & 167.69 & Dean \\
\hline
\end{tabular}


a)

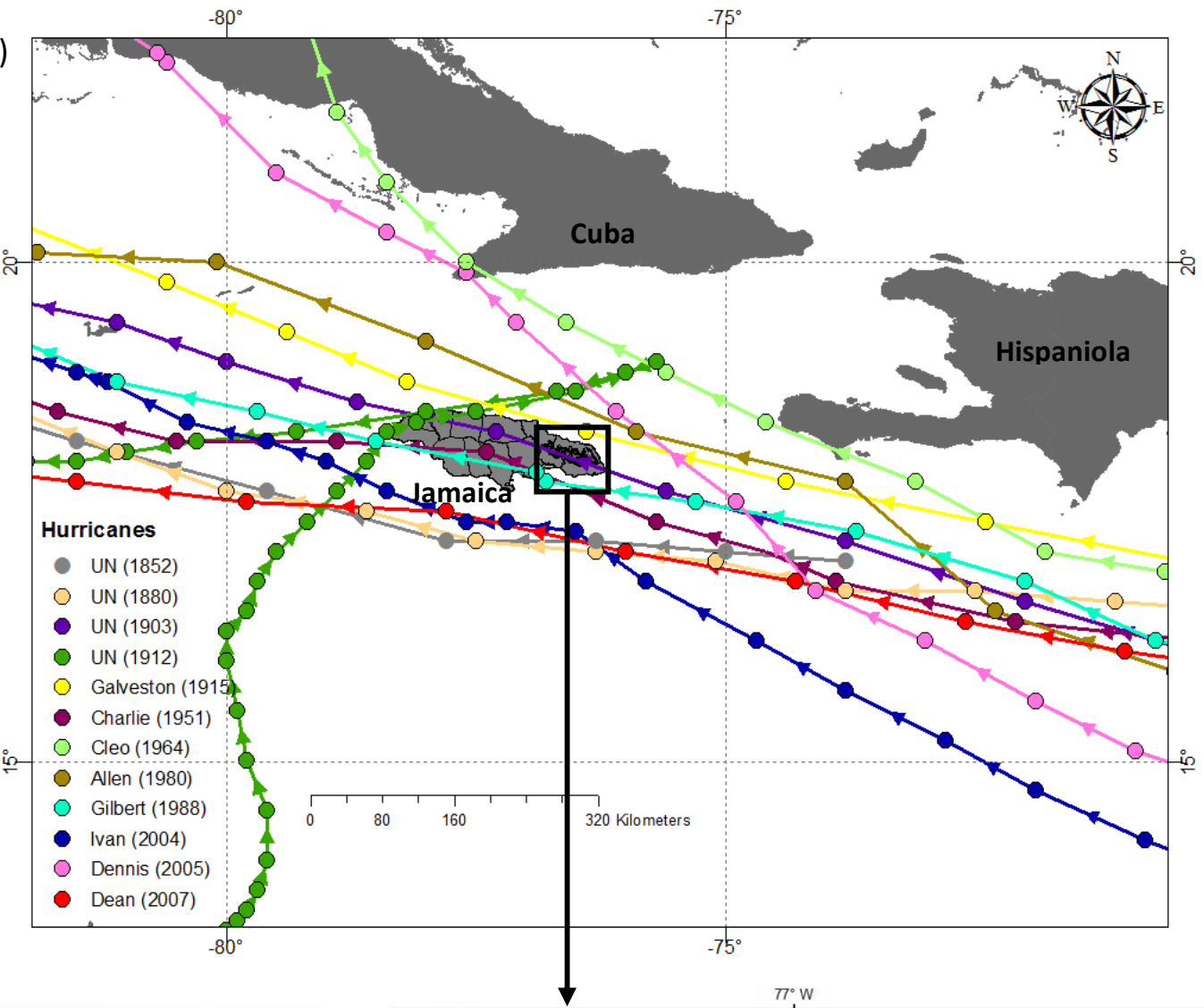

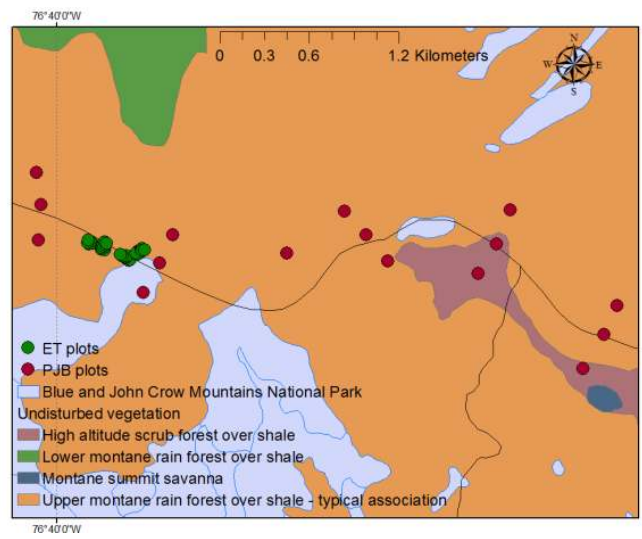

334

335

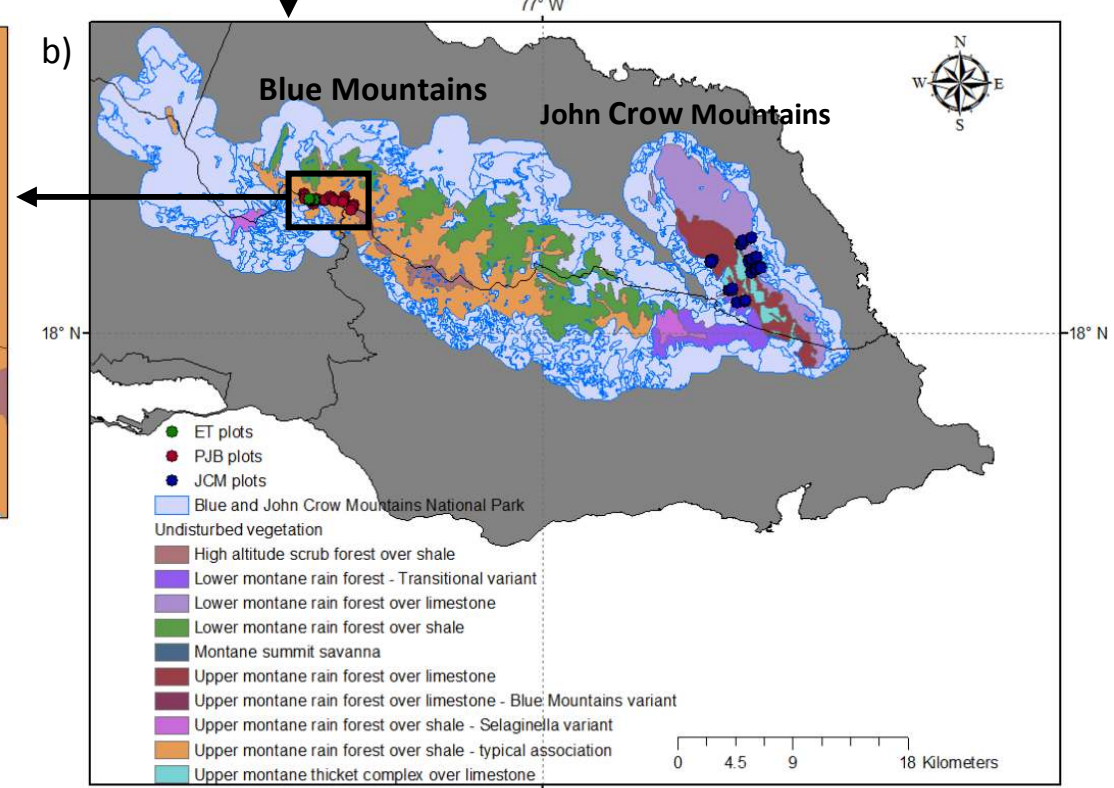

336

Upper montane rain forest over shale - typical asssociation 18 Kilometers

337 Figure 1. a) Tracks of hurricanes categorized as category 2,3 or 4 using the Saffir-Simpson

338 Hurricane Wind Scale, with centers that passed within 0-113 km of the northern or southern

339 coastline of Jamaica during 1852-2007. Exposure vulnerability of these hurricanes was

340 reconstructed. Also included are b) maps of the study site, the Blue and John Crow Mountains

341 National Park (source: Muchoney et al. 1994), showing the extent of several old growth

342 vegetation classes, and overlaid with the location of permanent sample plots (ET: Tanner (1977);

343 PJB: Bellingham (1991) and JCM: Luke et al. (2016a)) established in the Blue and John Crow

344 Mountains, Jamaica. The colour coded arrows show the direction of the hurricanes. 


\section{EV model evaluation data}

347 Luke et al. (2016a) used global site factor (GSF) (calculated from hemispheric photographs) data 348 collected six months after Hurricane Dean (in 2008) in PSPs located in the JCM to test how well 349 their EV model performed. Specifically, they used a spatially explicit generalized additive mixed 350 model (GAMM) to showed that the EV values, which were extracted from the EV maps using 351 the GSF plot location, explained the highest deviance in the GSF data and that GSF increased

352 significantly with Hurricane Dean EV (Luke et al. 2016a). In the present study, we used a similar 353 approach. In particular, we used a spatially explicit generalized linear mixed model (GLMM) 354 and damage and recovery data from Bellingham's and Tanner's plots to determine if the 355 reconstruction method accurately modelled sites that were exposed to Hurricane Gilbert. 356 Dependent variables used in the GLMM included percentage of stems in the plots that died, had 357 crown defoliation, and had resprouted in 1990 from Bellingham's plots. From Tanner's plots, the 358 dependent variables included percentage of stems with crown defoliation and resprouting in 1989 359 and 1991.

361 Based on previous stand-level assessments (Bellingham 1991), it was expected that plots with 362 the highest exposure would suffer greater hurricane damage and show evidence of a higher 363 percentage of recovering stems. Nevertheless, we evaluated the influence of several independent 364 variables on the damage and recovery data to determine if EV was the most important predictor. 365 As such, the independent variables included elevation, aspect, topographic position index (TPI) 366 and EV values for Hurricane Gilbert, which were extracted at each plot location. Elevation 367 values were obtained from the DSM, whereas aspect and TPI values were extracted from maps 
that were generated from the DSM. The TPI map was generated using the Land Facet Corridor Designer Tools for ArcGIS 10 (Jenness et al. 2013). TPI values are continuous and as they change from negative to positive this is indicative of a transition from valleys to slopes to ridge tops. Specifically, negative TPI values represent valleys and gullies, TPI values near zero represent mid-slopes, and positive and comparatively large TPI values represent ridges and ridge tops (Jenness et al. 2013). To determine the effects of hurricane proxy choice (Hurricane Dean QuikSCAT Scatterometer image) on EV map accuracy, the model evaluation was repeated for Gilbert EV maps reconstructed using other proxies such as Hurricanes Dean and Emily and average EV of the three proxy hurricanes. The accuracy of EV maps generated using the best single proxy, which was Hurricane Ivan, a proxy from the same Saffir-Simpson Hurricane Wind Scale category, which is Hurricanes Dean and Emily, and the average of the three proxies, was then compared. The statistical method used to evaluate the EV model is described below.

\section{Aggregating the spatial patterns of hurricane disturbance: modelling the influence of}

\section{hurricane direction and distance on exposure vulnerability}

Unless stated otherwise, statistical tests were performed using the $\mathrm{R}$ programming language ( $\mathrm{R}$ Development- Core-Team, 2017). The path of the hurricane is determined by the storm forward speed and direction. Both influence the angle of approach of the hurricane to an island or a landmass and the cardinal direction of the track of the hurricane. Bivariate plots of EV and aspect were therefore generated and inspected, and were used to determine the directional patterns of exposure based on the cardinal direction/angle of the track of a hurricane's eye. Before the data were plotted, a raster image of undisturbed upper montane forest in the BM (Figure 1) was converted to a point shp file. This was used to extract EV and aspect values from 
391 the respective maps. The polarPlot function from the 'openair' package (Carslaw and Ropkins, 392 2012) was then used to construct a bivariate plot of the relationship between EV and aspect for 393 each hurricane. This process involves creating a smooth surface by fitting a generalized additive 394 model (GAM) to the data. The level of smoothness is controlled by the smoothing parameter $k$ 395 and we used the default value (100). The polarPlot function and the resultant bivariate plot are 396 suitable for a graphical analysis but not for quantitative purposes. As such, directional 397 information on EV was discerned graphically when the smooth surface was plotted in polar 398 coordinates. Plots for the JCM were very similar to those of the BM, and therefore, they are not 399 presented. The relationships between the cardinal direction of the tracks of the eyes of the 400 hurricanes relative to the study sites and EV and distance from the eyes of the hurricanes to 401 the study sites and EVwere then explored (Figures 5-8). A polynomial (2nd-degree) model was 402 found to be the most suitable model for representing this relationship. As such, a pixel-level 403 (2nd-degree) polynomial regression analysis was conducted using the USGS Curve Fit extension 404 for ArcMap (De Jager and Fox, 2013). This was used to map the spatial patterns of exposure 405 based on the angle or cardinal direction of the track the hurricane's eye and distance to the 406 hurricane's eye, over the period 1852-2007. Curve Fit uses a linear or nonlinear regression to 407 calculate a unique mathematical model at each pixel of the input raster data sets (De Jager and 408 Fox, 2013). The input for the Curve Fit function included a time series of EV maps for the BM 409 and JCM (dependent variable), and the average angle or cardinal direction (in degrees) of the 410 track of the eye of each hurricane relative to the study sites or the distance to the eye of each 411 hurricane from the study sites, as an independent variable (Table 1). 
413 Before the exposure maps were added to the Curve Fit function, they were first clipped to an area

414 of interest that included only natural old growth (including old secondary) forest of the

415 predominant forest type found at both sites where the plots were established (Figure 1). This

416 helped to reduce processing time. The Curve Fit output products generated for this study

417 included the P-value, adjusted $\mathrm{R}^{2}$ and parameter a2 of the fitted polynomial regression, as image

418 files. The a 2 parameter is the regression coefficient for the squared term. If a $2>0$, then the

419 relationship with the response is convex or concave upward, whereas if a $<0$, then the

420 relationship is concave downward. The calc function in $\mathrm{R}$ can be used to generate similar outputs

421 and this was used to generate maps from a fitted pixel-level polynomial regression for the period

422 1852-1988. At each plot location, these values (from the Curve Fit image files) were extracted

423 and used in subsequent analyses. Bellingham's plots were likely to be influenced by hurricanes

424 that struck the island before the final census was conducted in 2004; therefore, only values from

425 the calc image files were extracted and used. Although adjacent pixels would likely influence the

426 EV value of a pixel, the pixel-level regression only considers a single pixel at a time and

427 generates a model for each pixel. Consequently, there was no spatial autocorrelation, but the data

428 were likely to be temporally autocorrelated. We therefore used the partial autocorrelation

429 function (PACF) and the autocorrelation function (ACF) to assess the residuals from polynomial

430 models developed using EV data extracted using the plot data to confirm that there was no

431 temporal autocorrelation, that is, they followed a white noise (random) process.

432

433

Bayesian hierarchical spatiotemporal/spatial model structure: EV model evaluation and the

434 effects of $E V$ and/or topographic features on tree diversity and density 
435 Tanner's plots were established according to a nested design, which included several contiguous

436 subplots nested within four plots or 'sites'. Also, the layout of Bellingham's plots followed a

437 fully systematic design and Luke et al.'s (2016a) plots followed a structured or a stratified

438 randomized block design. Consequently, Tanner's subplots were spatially pseudo-replicated and

439 auto-correlated because they were adjacent to each other in space. Additionally, the plots within

440 each transect of Bellingham (1991) and within each block of Luke et al. (2016a) were also close

441 enough to each other to potentially be spatially auto-correlated. Nested, systematic and structured

442 data can be fitted in a standard linear model with nested, systematic, that is, using each transect

443 as a block, and structured fixed effects. However, the degrees of freedom must be adapted to the

444 design of the study, because the errors will likely be spatially correlated and thus violating the

445 assumption of independent observations or errors. This must be accounted for by a model to

446 obtain accurate mean sum of squares (Gelman 2005; Schielzeth and Nakagawa 2013). As such,

447 data from the nested subplots, the transects and structured plots can only be appropriately

448 modelled using mixed effects models, which cluster the data in groups as a random effect

449 (Schielzeth and Nakagawa 2013; Zuur et al. 2017) and estimate the standard errors correctly

450 (Gelman 2005), because the latter will be biased if they are not corrected for clustering. A better

451 approach is to use a mixed-model with a spatial autocorrelation structure (using the coordinates

452 of the center of the subplots and plots), as the errors are allowed to be correlated and/or to have

453 unequal variances (Crawley 2012). However, some of the data were also likely to be temporally

454 auto-correlated; as a result, the most appropriate models should include spatial and temporal

455 autocorrelation structures. Nonetheless, the choice of frequentist methods that can cope with

456 these structures is limited, and the most appropriate methods require Bayesian statistics (Zuur et

457 al. 2017). Consequently, the models that were developed in this study were fitted using a 
458 Bayesian approach based on the Integrated Nested Laplace Approximation (INLA), implemented 459 using the 'INLA' package (Rue et al. 2009; Lindgren et al. 2011; Martins et al. 2013; Lindgren 460 and Rue 2015; Rue et al. 2017). The method was used due to its flexibility (see below) and 461 because the posterior marginal probabilities are approximated more efficiently and faster, when 462 compared with traditional MCMC approaches (Rue and Martino 2007; Rue et al. 2009).

464 Two types of model were developed: models with either a spatiotemporal random effect for 465 overall assessments, regardless of time, and models with a spatial random effect for each 466 individual census. Models were developed for EV model evaluation and to determine whether 467 average EV from several hurricanes, topographic parameters or data from the Curve Fit and the 468 calc function output products could be used to explain spatial and/or spatiotemporal patterns of 469 tree diversity and density in the BM and JCM. For the JCM, Luke et al. (2016a) reported the 470 results of assessments of the Shannon-Wiener $\left(\mathrm{H}^{\prime}\right)$ diversity index versus EV and topographic 471 parameters for individual censuses. As such, in the present study, only the influence of the Curve

472 Fit output products was checked for the individual census periods. The models were developed

473 following a spatially explicit generalized linear mixed model (GLMM) framework. The response

474 variable at a given plot location and census interval was assumed to have a distribution that

475 belonged to the exponential family. As such, suitable distributions and link functions were 476 chosen for the response variables. For the EV model evaluation exercise, the response variables

477 were expressed as a percentage of the stems found in each plot (percentage defoliated, resprouted 478 and dead stems) and as such, either a binomial (BIN), or a zero-inflated binomial Type 0 (ZIB.0) 479 with a logistic link function was used. The ZIB.0 was chosen if the data had four or more zero 480 values and it was deemed a better fit. The dependent variables in the other models were either $\mathrm{H}^{\prime}$ 
481 values or density values for each plot that was sampled during the periods 1974-2009 (Tanner's

482 plots), and 1991-2004 (Bellingham's plots) in the BM, and 2006-2012 (Luke et al.’s (2016a)

483 plots) in the JCM. For H' values derived from Tanner's plots, a Gaussian distribution was used.

484 A Gamma distribution and log-link function were used for $\mathrm{H}^{\prime}$ and density values derived from

485 Bellingham's and Luke et al.'s (2016a) plot data. A value of 0.00001 was added to the density

486 values, because a Gamma distribution does not include zeros.

487

488 The parameters of the chosen exponential family $(\phi)$ were linked to a structured additive

489 predictor $\eta$ through their canonical link function $g(\cdot)$, such that $g(\phi)=\eta$. The linear predictor was

490 defined as:

$$
\eta=\beta_{0}+\beta_{1} * \operatorname{Var} .1+\beta_{2} * \operatorname{Var} .2+f(\operatorname{Var} .3)+f(s, t)
$$

492 where $\eta$ was the linear predictor for any one of the response variables, $\beta_{0}$ was the intercept, $\beta_{1}$ 493 and $\beta_{2}$ were the regression coefficients for the predictors Var.1 and Var.2, and Var.3 was also a 494 covariate/predictor. In general, the semiparametric function $f(\cdot)$ can be used either to relax the 495 linearity of the covariates/predictors, that is smooth effects similar to a GAM, or it can be used to 496 define either the spatial or spatiotemporal random effect (Rue et al., 2009). In this study, $f(\cdot)$ was 497 used to model the smooth, non-linear effects of some covariates/predictors using either a first498 order or second-order random walk process (RW1 or RW2) given by $f(\operatorname{Var} .3)$. A polynomial 499 INLA spatiotemporal model was used to confirm that there was a non-linear relationship 500 between the response and the predictor before smoothing was applied, i.e. that all the degrees or 501 the orders of the polynomial were important. The $f(\cdot)$ was also used to represent the effects of the 502 spatial position of each plot location (using the coordinates taken at the center of each plot) by 503 allowing for the inclusion of a spatially structured random effect $f(s)$, and for the spatiotemporal 
models this followed an autoregressive process $f(s, t)$. The latter represented a Matérn correlation structure but with a different realization every year (Cosandey-Godin et al. 2014).

The spatially-structured random effect was modeled by a Gaussian random field (GRF) using the stochastic partial differential equation (SPDE) approach of Lindgren et al. (2011). A GRF with a Matérn covariance function can be represented as a Gaussian Markov Random Field (GMRF) (Lindgren et al. 2011). A GMRF is a spatial process that models the spatial dependence of data observed on a regular grid, lattice or geographic region (Cameletti et al. 2013). The SPDE approach is used to find a GMRF with local neighbourhood and sparse precision matrix $\mathbf{Q}$ (i.e., the inverse of the covariance matrix) that best represents the Matérn field (Lindgren et al. 2011), to avoid the "big n problem" that occurs with large spatiotemporal datasets (Banerjee et al 2004). The SPDE method achieves this by allowing for the evaluation of the continuous GRF as a discretely-indexed random process (i.e. a Gaussian Markov Random Field; Lindgren and Rue 2015). In particular, the SPDE method subdivides the domain, in this case the area of interest where the plots were established (the forests of the BM and JCM), into non-intersecting triangles creating an index mesh, instead of a regular grid (Lindgren et al. 2011). Linear combinations of basis functions, defined on the locations of the set of vertices, are used in the triangulation to represent the field (Lindgren et al. 2011). The meshes that were used to approximate the spatial fields for the BM and JCM are shown in Appendix S1. The meshes were confined to the area of interest for both sites. Different mesh sizes were used for both sites, including a mesh that only encompassed the plot locations. This was gradually extended to include the entire study area for each site. Also, the mesh should typically be extended beyond the study area to reduce boundary effects where the variance is twice as large as inside the domain. For this study, the final mesh 
527 used for either site yielded very similar results as the mesh size increased. As such, the final

528 mesh that was bounded by the area of interest was used. For a more detailed explanation of the

529 SPDE approach see Lindgren et al. (2011).

530

531 The sampling times for Tanner's and Bellingham's plot censuses were unequally spaced, so for

532 the models they were treated as data collected over a continuous time domain and were

533 discretized over a set of knots, with equal spacing over the sample period. When applying

534 models with spatial correlation, a 2-D mesh is defined (Zuur et al. 2017). When knots are used, a

535 1-D mesh that is dependent on knot values is constructed (Zuur et al. 2017) and, similar to the

536 spatial model, piecewise linear basis functions are used, but at a set of time knots (Krainski et al.

537 2017). The knot values are used to calculate weighting factors that are inversely proportional to

538 the distance between the sampling year and the knots (Zuur et al. 2017). To fit the space-time

539 continuous model, the time knots and the temporal mesh need to be determined. Specifically, the

540 seven and three sample times for Tanner's and Bellingham's plot data were discretized over four

541 and three knots, respectively (Appendix 1). For Tanner's plots, the knots represented the years

542 1974, 1985.7, 1997.3 and 2009, whereas for Bellingham's plots, the knots represented the years

543 1990, 1997 and 2004. The final model was specified as a SPDE model for the spatial domain and

544 an AR(1) model for the time dimension. This model allowed for the simulation of the conditional

545 marginal distribution at each time, that is, it simulated a realization of the spatial random field for

546 each time. Two space-time models were used: one for discrete time domain (two years for the

$547 \mathrm{JCM}$ ) and for the second model, time was discretized over a set of knots (for the BM). 
549 Before the statistical tests were performed, significantly correlated independent variables (with a

550 correlation $>0.5$ ) were identified using Spearman's rho statistic and test. The Deviance

551 Information Criterion (DIC), which was computed by R-INLA, was used to compare the

552 goodness-of-fit of the models. The DIC is comparable to the Akaike Information Criterion

553 (AIC), but it is more suitable for hierarchical Bayesian models (Spiegelhalter et al. 2002).

554 Models with the lowest DIC values were generally considered as the best models. In addition, 555 the marginal R-squared (following Zheng (2000)) was calculated as follows:

$$
100 *\left(1-\left(\sum_{t=1}^{t} \sum_{n=1}^{n}(\text { depend }- \text { fitted }) 2 / \sum_{t=1}^{t} \sum_{n=1}^{n}(\text { depend }- \text { mean }(\text { depend })) 2\right)\right) \text {, }
$$

557 where $t$ is time when $n$ subjects were considered, depend is the response variable, and fitted is the

558 values predicted by the model. The most parsimonious final models that included independent

559 variables, which were not significantly correlated, were identified and reported. Model fit was

560 also evaluated using scatter plots of the observed and predicted data and quantile-quantile

561 residual plots. In addition, INLA performs a 'leave out one' cross-validation from which two

562 indices that can be used to evaluate model predictive performance are computed (Blangiardo and

563 Cameletti 2015): the probability integrity transform (PIT) (Dawid 1984) and the conditional

564 predictive ordinate (CPO) (Pettit 1990). The empirical distribution of the PIT can be used to

565 evaluate model predictive performance (Gneiting et al. 2007). If a histogram of the PIT values

566 follows a uniform distribution, this means that model predications are coherent with the observed

567 data (Blangiardo and Cameletti 2015). In addition, when the PIT and CPO indexes are computed,

568 numerical problems can occur (Held et al. 2010). The 'failure' vector automatically provided by

569 INLA contains a value of 0 or 1 for individual observations (Blangiardo and Cameletti 2015). A

570 value of 1 indicates that for a particular observation, the predictive measures are not reliable due

571 to some problems with the calculation (Blangiardo and Cameletti 2015). If the vector is summed, 
572 a value of 0 indicates that no failures were detected. Final models were not selected unless the

573 sum of the CPO was equal to 0 and a histogram of the PIT values showed a uniform distribution.

575 In most cases, the default and recommended priors were used; specifically, vague priors or 576 estimations of non-informative priors (Cosandey-Godin et al. 2014). However, to avoid 577 overfitting, the penalized complexity prior (PC-prior) framework was adopted. A PC-prior 578 derived by Fuglstad et al. (2019) was used to define the model parameters of the SPDE model as 579 the practical range and the marginal standard deviation. It is weakly informative, and complexity 580 is penalised by shrinking the range to infinity and the marginal variance to zero (Fuglstad et al.

581 2019). For the SPDE, the PC-prior ensured that the spatially structured effect operated at a 582 similar but not smaller spatial scale as the model covariates/predictors. Otherwise, the spatial 583 effect would explain the data better than the covariates, rendering the model meaningless while 584 inflating model accuracy and the marginal R-squared and deflating the DIC, rendering them 585 useless for model selection. Several values for the range were used (starting with half the 586 distance between the farthest points), until there was no overfitting. A PC-prior, developed by 587 Simspon et al. (2017), was also considered for the random walk processes (RW1 and RW2). It 588 requires defining a reference standard deviation $\sigma_{0}$ and the right-tail probability $u$, as $\mathrm{P}\left(\sigma_{0}>\sigma\right)=$ $589 u$ (Simspon et al. 2017). The PC-prior controlled the level of smoothness and a value of 1 for $\sigma_{0}$ 590 is the suggested starting point. Using lower values will result in a smoother fit and progressively 591 lower values will give a straight line.

593 Before the models were accepted, several ways in which EV could be used to explain 594 spatiotemporal trends were first explored. Average 'legacy' EV calculated from multiple 
595 hurricanes that affected a site before a census, with no adjustment for time (since each hurricane 596 affected the sites/plots), was found to be the best predictor of diversity in the JCM (Luke et al.

597 2016a). In the present study, we found that average 'legacy' EV was more suitable for assessing

598 the overall effects of EV when multiple re-numeration times were used in the models (Figure 9).

599 However, we used a manual stepwise forward selection approach to identify the best or most

600 suitable hurricanes and the number of hurricanes for averaging. Specifically, EV values for each

601 hurricane were first included in a regression model with a response variable (diversity or

602 density), and important EVs were identified. The two most important EVs (based on DIC and the 603 marginal R-squared values) were then averaged and model fit, that is the DIC and the marginal

604 R-squared values, was assessed. If model fit was improved by averaging the two most important

605 hurricane EVs, that is if the DIC decreased and the marginal R-squared increased, additional EVs 606 were then included in the average. If model fit did not improve when the EV of a hurricane was

607 included in the average, it was dropped. This was repeated until an average 'legacy' EV that 608 yielded the lowest DIC and the highest marginal R-squared values was identified. This was then 609 used to identify the most parsimonious model.

611 The most parsimonious final models were identified using a manual stepwise backward selection 612 approach and were reported. Specifically, important predictors with the highest marginal R613 squared and the lowest DIC were identified, and other predictors that were correlated with these 614 predictors but had a lower marginal R-squared and higher DIC were dropped. If there were $>1$ 615 uncorrelated predictors, they were all included in a model and the final model was accepted if 616 they were all important. If one or more of the predictors were not important when they were 617 added to the model, they were dropped until the most parsimonious model was identified. These 
618 619

620

\section{Results}

622 The nominal range, which is the minimum distance at which data from two plot locations are 623 uncorrelated (or correlation between the two plots is $\leq 0.1$ ), varied for the models that were used 624 to analyze plot data from the two study sites. For all the models that included Tanner's plot data, 625 the nominal range was $5.1-8.2 \mathrm{~km}$, for Bellingham's plot data $4.7-8.4 \mathrm{~km}$ and for Luke et al.'s 626 (2016a) plot data 5.9-8.4 km (Tables 2-8). For the assessments (e.g. EV versus tree diversity or 627 density) that included all the censures (i.e. assessing the overall effects regardless of time), the 628 data used were not found to be temporally auto-correlated; but in all cases model fit improved 629 with the inclusion of spatiotemporal random effects. In addition, for all models, the variance of 630 the spatial effect was lower than that of the model variance (Tables 2-8).

631

\section{EV model evaluation}

633 For the BM, damage and recovery data from Bellingham's plots, in particular completely 634 defoliated and reprouting stems, were found to increase significantly with Hurricane Gilbert EV 635 (Figure 2a,b; Table 2), with marginal R-squared $\left(\mathrm{mR}^{2}\right)$ values of $37.5 \%$ and $47.1 \%$, respectively 636 (Table 2). This indicated that the method used to reconstruct the EV of past hurricanes generated 637 maps of EV that can be considered as a proxy to damage caused by these hurricanes. In addition, 638 the best proxy for Hurricane Gilbert, that is an EV map created using metrological data from a 639 processed QuikSCAT Scatterometer image of Hurricane Ivan, could be used to explain the 640 damage and recovery data from Bellingham's plots. Average EV from three proxies (Hurricanes 
641 Emily, Ivan and Dean; $\left.\mathrm{mR}^{2}=36.2 \%\right)$, and the other proxies $\left(\mathrm{mR}^{2}=30.1 \%\right.$ (Dean) and $\mathrm{mR}^{2}=$ $64227.2 \%$ (Emily)) could only be used to explain the recovery data (Figures 2c-e; Table 2).

643 Therefore, in the absence of a single 'best' proxy, proxy images of other hurricanes from the 644 same Saffir-Simpson Hurricane Wind Scale category or the average of three proxies from the 645 same wind scale category, could, at the very least, be used to represent forest recovery from 646 hurricanes. The percentage of dead stems was better explained by elevation, that is dead stems 647 increased with elevation $\left(\mathrm{mR}^{2}=44.6 \%\right)$ (Figure $2 \mathrm{f}$; Table 2$)$. If data from Tanner's plots were 648 used, defoliated stems showed an S-shaped non-linear relationship with TPI $\left(\mathrm{mR}^{2}=66.1 \%\right)$, 649 indicating that the topographic location of the plots had a greater influence on hurricane damage 650 than was the case for Bellingham's plots, and in this case, damage was highest at or near ridge 651 crests (Figure 2g; Table 3). A similar pattern was reported by Bellingham et al. (1992) and 652 Tanner et al. (2014). Similarly, resprouting in 1989 and 1991 was explained by TPI being highest 653 at or near ridge crests $\left(\mathrm{mR}^{2}=40.3\right.$ and $60.8 \%$, respectively) (Figure $2 \mathrm{~h} \mathrm{\&} \mathrm{j;} \mathrm{Table} \mathrm{3).}$

654

655

656

657

658

659

660

661

662

663 

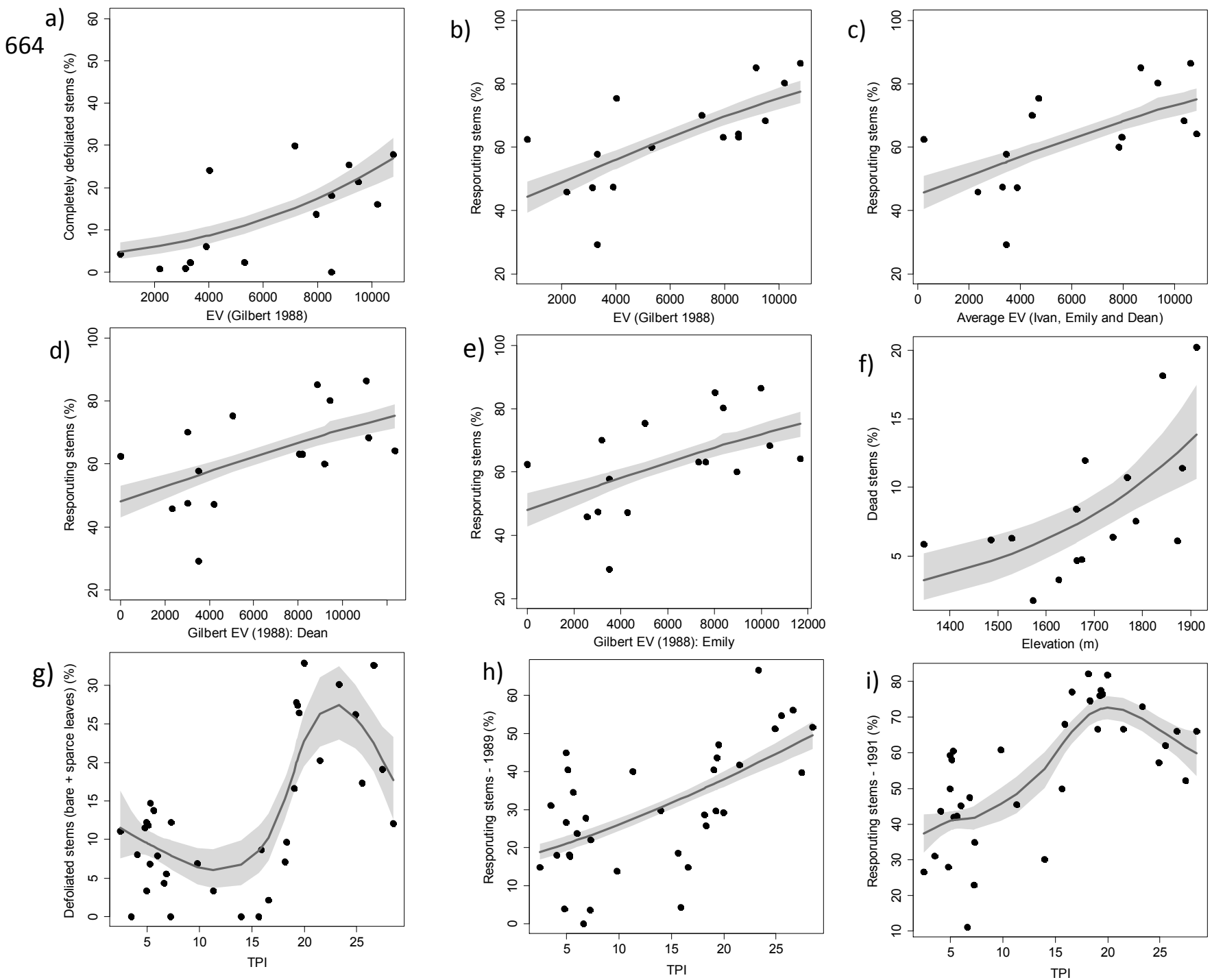

Figure 2. Observed (closed circles) and posterior mean predicted values (solid lines) and the 95\% credible intervals (shade) obtained from hierarchal Bayesian spatial models used to assess the relationship between damage and recovery data obtained from Bellingham's $(\mathrm{a}-\mathrm{f})$ and Tanner's (g-i) plots several months after the passage of Hurricane Gilbert in 1988, and the reconstructed Hurricane Gilbert exposure vulnerability (EV) based on three proxy hurricanes (in the order of model fit: Ivan, the average of all three hurricanes, Dean and Emily) and other topographic parameters (elevation and topographic position index (TPI)). 
672 Table 2. Summary of the marginal posterior distribution for model parameters obtained from

673 hierarchical INLA Bayesian models used to assess the relationship between damage and

674 recovery data from Bellingham's plots and Hurricane Gilbert exposure vulnerability (EV),

675 reconstructed using several proxy hurricanes including Hurricanes Ivan (2004), Dean (2007),

676 Emily (2005) and average (mean) EV from all three proxies that were found to be the most

677 important predictors ( $95 \%$ credible intervals did not contain zero) of damage and recovery in the

678 montane forest of the Blue Mountains, Jamaica, after the passage of Hurricane Gilbert in 1988.

\begin{tabular}{|c|c|c|c|c|c|c|c|c|}
\hline Year & Variable & Parameters & Mean & $Q_{0.025}$ & $Q_{0.975}$ & $\mathbf{m R}^{2}$ & DIC & Priors \\
\hline \multirow{5}{*}{1989} & \multirow{5}{*}{$\begin{array}{l}\text { Completely } \\
\text { defoliated } \\
\text { stems (\%) } \\
\text { ZIB.0 }\end{array}$} & Intercept & -3.2 & -3.6 & -2.7 & \multirow[t]{5}{*}{37.5} & \multirow[t]{5}{*}{155.7} & \\
\hline & & Glibert (Ivan) & 0.0002 & 0.0001 & 0.0003 & & & \\
\hline & & obs.var & 6.7 & 2.5 & 17.5 & & & \\
\hline & & spde.var.nom & 0.0000295 & -0.0000004 & 0.0002002 & & & $0.0023,0.5$ \\
\hline & & spde.range.nom & 6.5 & 0.7 & 30.8 & & & $3.9,0.5$ \\
\hline \multirow[t]{4}{*}{1989} & \multirow{4}{*}{$\begin{array}{l}\text { Resprouting } \\
\text { stems }(\%) \\
\text { BIN }\end{array}$} & Intercept & -0.3 & -0.6 & -0.1 & \multirow[t]{4}{*}{47.1} & \multirow[t]{4}{*}{159.2} & \\
\hline & & Glibert (Ivan) & 0.0001 & 0.0001 & 0.0002 & & & \\
\hline & & spde.var.nom & 0.0000196 & -0.0000004 & 0.0001245 & & & $0.0023,0.5$ \\
\hline & & spde.range.nom & 8.1 & 0.7 & 41.3 & & & $3.9,0.5$ \\
\hline \multirow[t]{4}{*}{1989} & \multirow{4}{*}{$\begin{array}{l}\text { Resprouting } \\
\text { stems }(\%) \\
\text { BIN }\end{array}$} & Intercept & -0.19 & -0.42 & 0.06 & \multirow[t]{4}{*}{36.2} & \multirow[t]{4}{*}{178.1} & \\
\hline & & Glibert (Mean) & 0.0001 & 0.0001 & 0.0002 & & & \\
\hline & & spde.var.nom & 0.0000197 & -0.0000005 & 0.0001238 & & & $0.0023,0.5$ \\
\hline & & spde.range.nom & 8.2 & 0.8 & 42.0 & & & $3.9,0.5$ \\
\hline \multirow[t]{4}{*}{1989} & \multirow{4}{*}{$\begin{array}{l}\text { Resprouting } \\
\text { stems }(\%) \\
\text { BIN }\end{array}$} & Intercept & -0.07 & -0.28 & 0.19 & \multirow[t]{4}{*}{30.1} & \multirow[t]{4}{*}{187.8} & \\
\hline & & Glibert (Dean) & 0.0001 & 0.0001 & 0.0001 & & & \\
\hline & & spde.var.nom & 0.0000251 & -0.0000004 & 0.0001666 & & & $0.0023,0.5$ \\
\hline & & spde.range.nom & 7.4 & 0.7 & 36.6 & & & $3.9,0.5$ \\
\hline \multirow[t]{4}{*}{1989} & \multirow{4}{*}{$\begin{array}{l}\text { Resprouting } \\
\text { stems }(\%) \\
\text { BIN }\end{array}$} & Intercept & -0.06 & -0.29 & 0.30 & \multirow[t]{4}{*}{27.2} & \multirow[t]{4}{*}{192.5} & \\
\hline & & Glibert (Emily) & 0.0001 & 0.0001 & 0.0001 & & & \\
\hline & & spde.var.nom & 0.0000277 & -0.0000004 & 0.0001863 & & & $0.0023,0.5$ \\
\hline & & spde.range.nom & 7.1 & 0.7 & 34.3 & & & $3.9,0.5$ \\
\hline \multirow[t]{4}{*}{1989} & \multirow{4}{*}{$\begin{array}{l}\text { Dead stems } \\
(\%) \\
\text { BIN }\end{array}$} & Intercept & -7.2 & -9.6 & -5.0 & \multirow[t]{4}{*}{44.6} & & \\
\hline & & Elevation & 0.0028 & 0.0015 & 0.0042 & & & \\
\hline & & spde.var.nom & 0.0000194 & -0.0000004 & 0.0001235 & & & $0.0023,0.5$ \\
\hline & & spde.range.nom & 7.3 & 0.7 & 35.7 & & & $3.9,0.5$ \\
\hline
\end{tabular}

$679 \mathrm{Q}_{0.025}$, and $\mathrm{Q}_{0.975}=$ quantiles of the credible interval; DIC $=$ Deviance Information Criterion; $\mathrm{mR}^{2}=$

680 marginal R-squared; ZIB.0 = zero inflated binomial Type 0 likelihood; BIN = Binomial likelihood;

681 obs.var $=$ model variance; spde. var.nom $=$ nominal spatial variance $($ priors $=$ prior marginal standard

682 deviation and right tail probability); spde.range.nom $=$ nominal spatial range $(\mathrm{km})$ (priors = practical

683 range and right tail probability).

684

685

686

687

688 
689 Table 3. Summary of the marginal posterior distribution for model parameters obtained from

690 hierarchical INLA Bayesian models used to assess the relationship between damage and

691 recovery data from Tanner's plots and topographic parameters (topographic position index (TPI))

692 that were found to be the most important predictors (95\% credible intervals did not contain zero)

693 of damage and recovery in the montane forest of the Blue Mountains, Jamaica, after the passage

694 of Hurricane Gilbert in 1988.

\begin{tabular}{|c|c|c|c|c|c|c|c|}
\hline Year & Variable & Parameters & Mean & $\mathbf{Q}_{0.025}$ & $\mathbf{Q}_{0.975}$ & $\mathbf{m R}^{2}$ & Priors \\
\hline \multirow[t]{5}{*}{1989} & \multirow{2}{*}{$\begin{array}{l}\text { Defoliated stems (\%) } \\
\text { ZIB.0 }\end{array}$} & Intercept & -1.94 & -2.06 & -1.82 & \multirow[t]{5}{*}{66.1} & \\
\hline & & obs.var & 183.4 & 7.5 & 964.5 & & \\
\hline & \multirow[t]{3}{*}{ RW2 } & TPI.var & 0.13 & 0.04 & 0.30 & & $0.1,0.05$ \\
\hline & & spde.var.nom & 0.0000183 & -0.0000004 & 0.0001149 & & $0.0023,0.5$ \\
\hline & & spde.range.nom & 8.2 & 0.8 & 42.0 & & $3.9,0.5$ \\
\hline \multirow[t]{5}{*}{1989} & \multirow{5}{*}{$\begin{array}{l}\text { Resporuting stems (\%) } \\
\text { ZIB.0 }\end{array}$} & Intercept & -1.60 & -1.76 & -1.44 & \multirow[t]{5}{*}{40.3} & \\
\hline & & TPI & 0.06 & 0.05 & 0.06 & & \\
\hline & & obs.var & 44.1 & 8.1 & 166.3 & & \\
\hline & & spde.var.nom & 0.0000406 & -0.0000007 & 0.0002875 & & $0.0023,0.5$ \\
\hline & & spde.range.nom & 5.3 & 0.5 & 23.4 & & $3.9,0.5$ \\
\hline \multirow[t]{5}{*}{1991} & \multirow{5}{*}{$\begin{array}{l}\text { Respor } \\
\text { ZIB.0 } \\
\text { RW2 }\end{array}$} & Intercept & 0.20 & 0.13 & 0.28 & \multirow[t]{5}{*}{60.8} & \\
\hline & & obs.var & 183.4 & 7.5 & 964.5 & & \\
\hline & & TPI.var & 0.027 & 0.009 & 0.061 & & $0.03,0.05$ \\
\hline & & spde.var.nom & 0.0000379 & -0.0000005 & 0.0002664 & & $0.0023,0.5$ \\
\hline & & spde.range.nom & 5.1 & 0.5 & 22.3 & & $3.9,0.5$ \\
\hline
\end{tabular}

$695 \mathrm{Q}_{0.025}$ and $\mathrm{Q}_{0.975}=$ quantiles of the credible interval; $\mathrm{mR}^{2}=$ marginal R-squared (\%); RW2 = second-order

696 random walk process (predictor variance is followed by .var, e.g., TPI.var for RW2 and Prior $=$ reference

697 standard deviation and the right tail probability); ZIB.0 = zero inflated binomial Type 0 likelihood;

698 obs.var $=$ model variance; spde. var.nom $=$ nominal spatial variance $($ Priors $=$ prior marginal standard

699 deviation and right tail probability); spde.range.nom $=$ nominal spatial range $(\mathrm{km})($ Priors $=$ practical

700 range and right tail probability). 

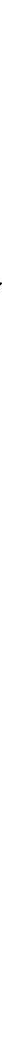

(1880)
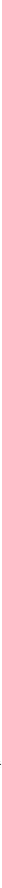

N (1903)
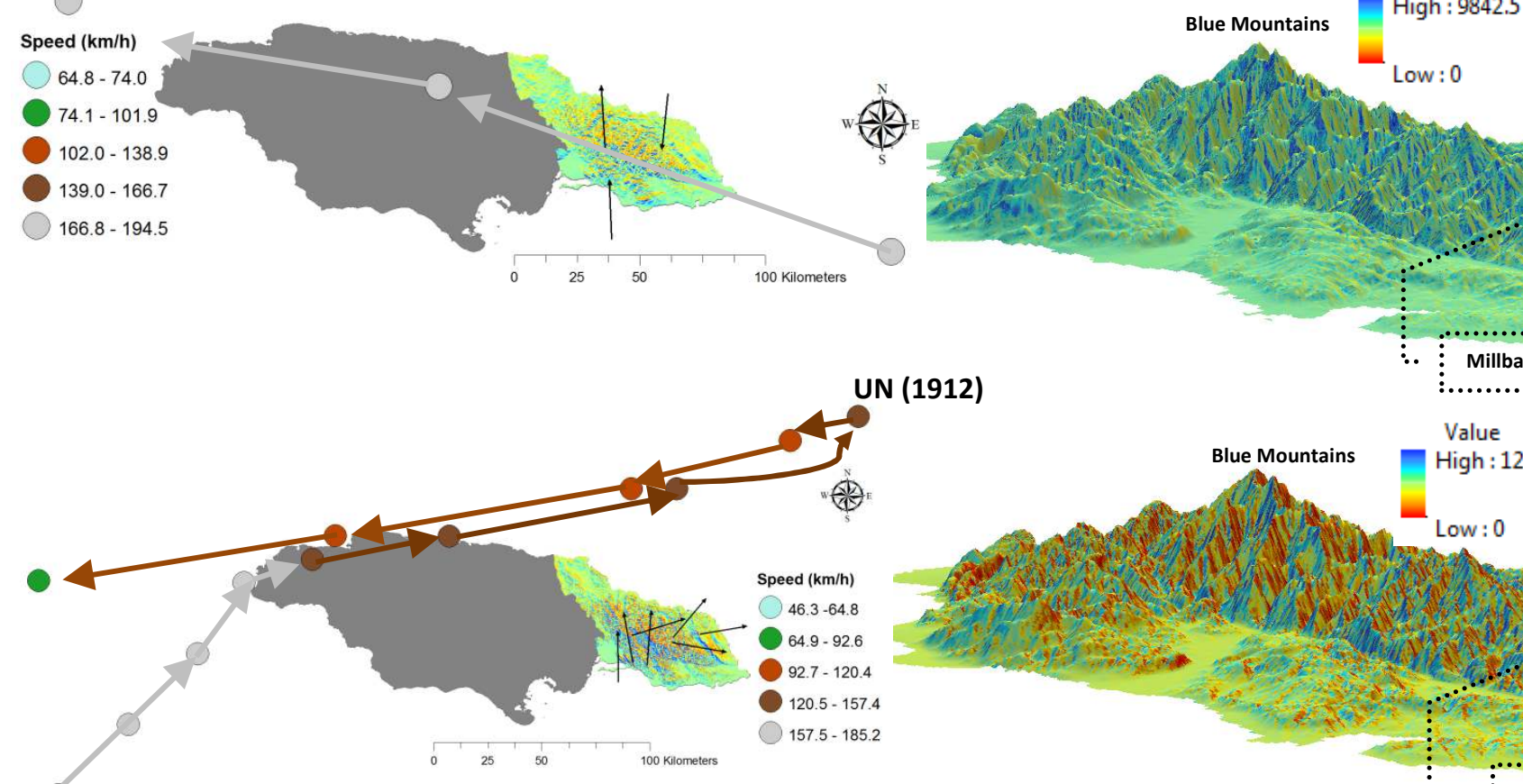

John Crow Mountains

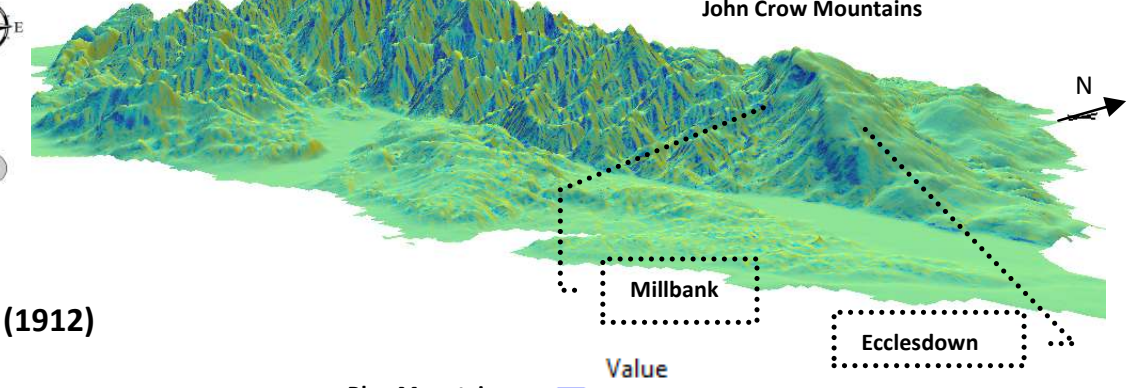

707 Figure 3. Exposure vulnerability (EV) maps (three-dimensional view) for category 2, 3 or 4

708 hurricanes, with centers that passed within $0-113 \mathrm{~km}$ of the northern or southern coastline of

709 Jamaica, during the period 1852-1988. The two-dimensional inserts include hurricane tracks and

710 direction (closed circles with arrows) with information on wind speed at each track location and

711 wind direction (black arrows). Value = highest and lowest EV values. UN = unnamed hurricane. 


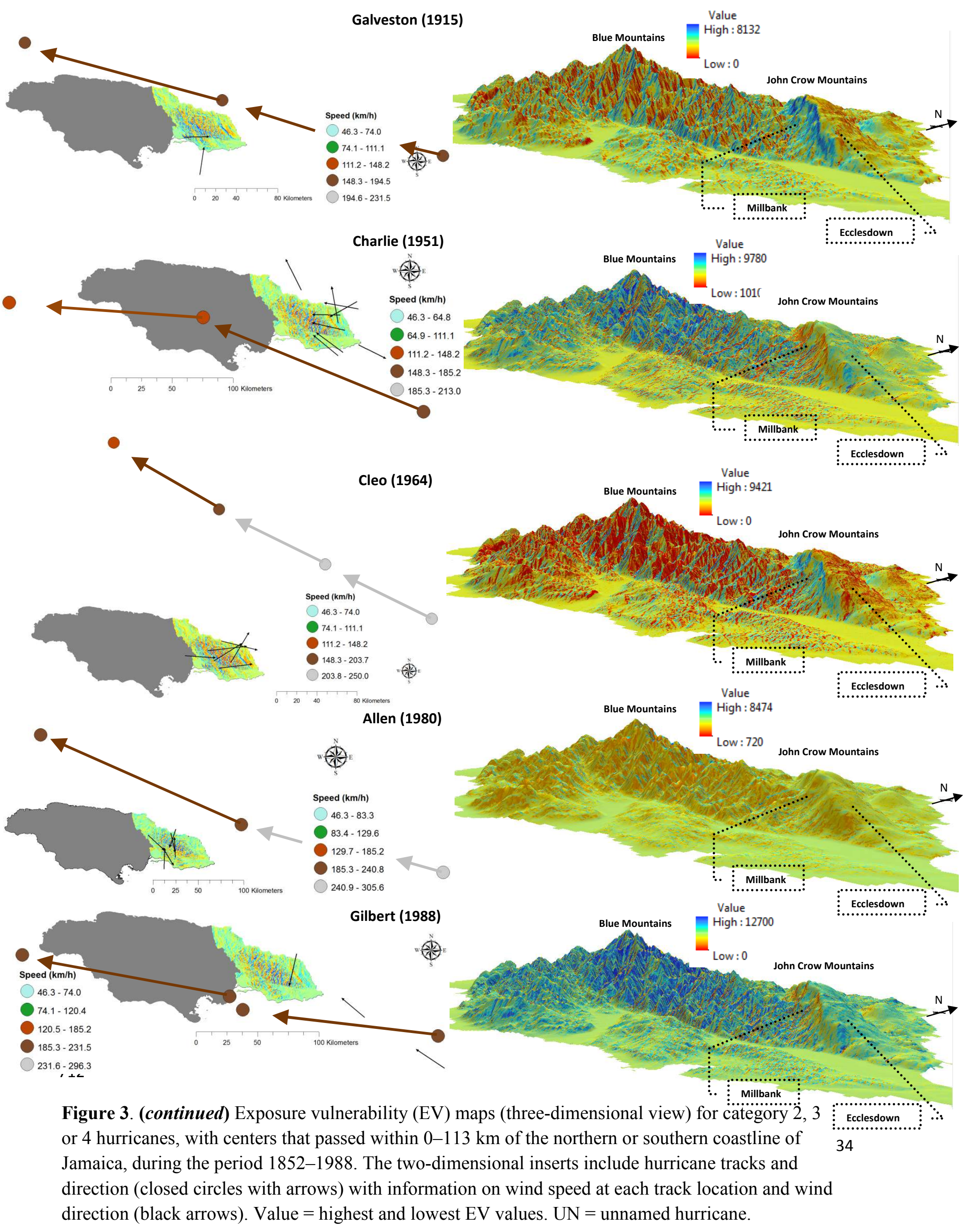




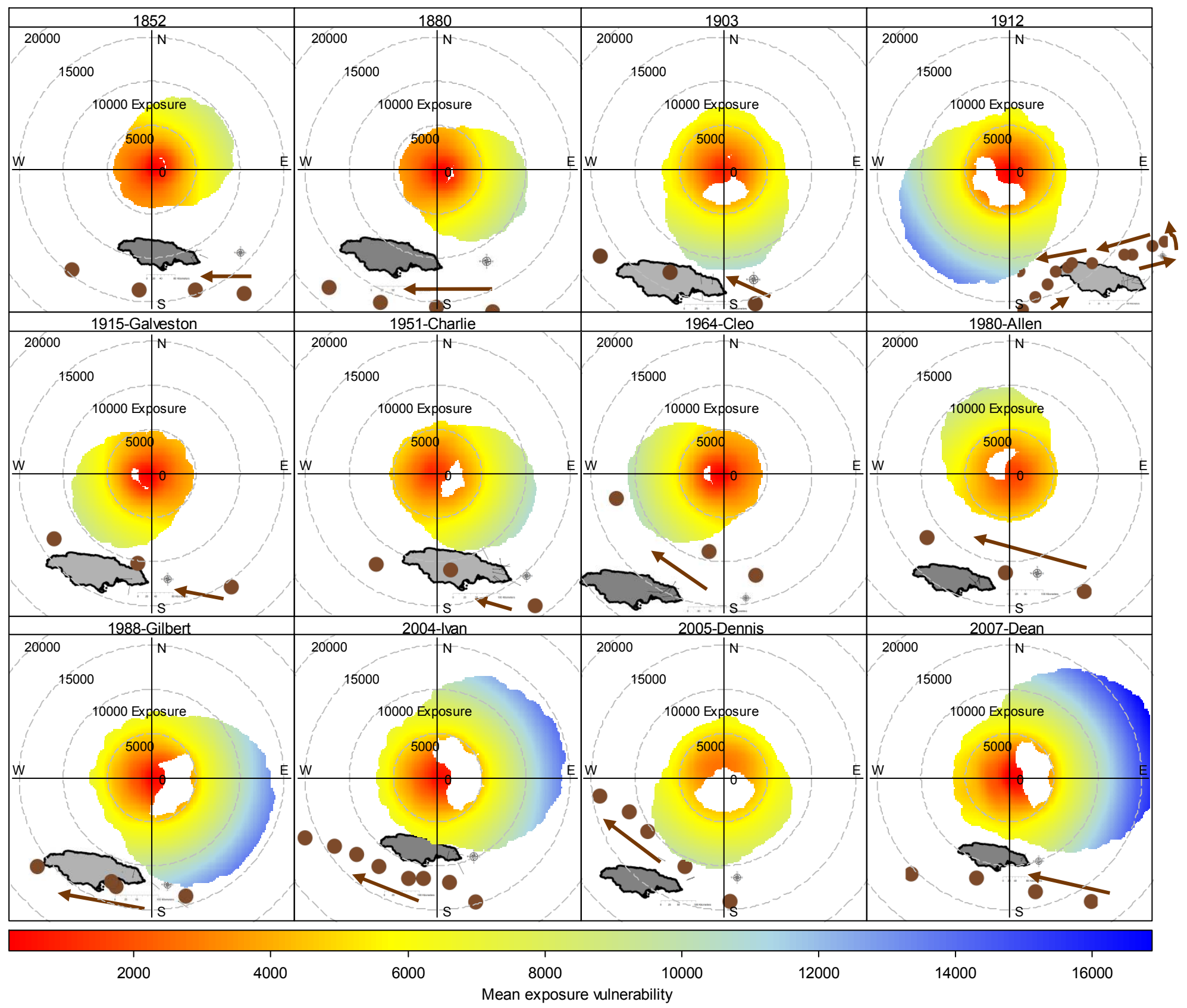

713 Figure 4. Bivariate polar plots (in polar coordinates) of aspect and exposure vulnerability (EV or

714 Exposure) for each hurricane with insert maps showing hurricane tracks (brown closed circles)

715 relative to the island of Jamaica. The polar plots show the aspect (or direction) with the highest

716 and lowest EV values when each hurricane affected the Blue Mountains. Arrows show the

717 direction of the hurricane tracks. The map inserts were placed where they can be viewed. 


\section{Long-term exposure in the Blue and John Crow Mountains}

722 EV was found to be directional depending on the angle or cardinal direction of the track of the 723 eye of each hurricane as it passed relative to the two study sites (Figures 3 and 4). If the track of 724 a hurricane's eye passed the sites at angles or cardinal directions ranging from $279^{\circ}$ to $41^{\circ}$, it 725 passed along a trajectory from north-east to north-west of the study sites if it made landfall, or if

726 it passed along the northern coastline (Figures 1, 3 and 4; Table 1). Due to the counter-clockwise 727 rotation of hurricane winds, this resulted in southern to western aspects being more exposed 728 (Figure 4). If the track of a hurricane's eye passed the sites at angles or cardinal directions 729 ranging from $167^{\circ}$ to $216^{\circ}$, it passed along a south-eastern to a south-western direction relative to 730 the study sites if it made landfall, or it passed along the southern coastline (Figures 1, 3 and 4; 731 Table 1). This resulted in north-eastern to south-eastern aspects being more exposed (Figure 4). 732 Maximum EV was lower for reconstructed hurricanes that made landfall when compared with 733 the three most recent hurricanes that did not make landfall. The reason for this discrepancy was 734 that maps for the three most recent hurricanes were created using actual images of each hurricane 735 and the EV maps were therefore more accurate. If the maximum EV values from the 736 reconstructed hurricanes were compared, the hurricanes that made landfall all had a higher 737 maximum EV value, unless wind speed at the eye was lower than that of the eye or outer bands 738 of other hurricanes. 


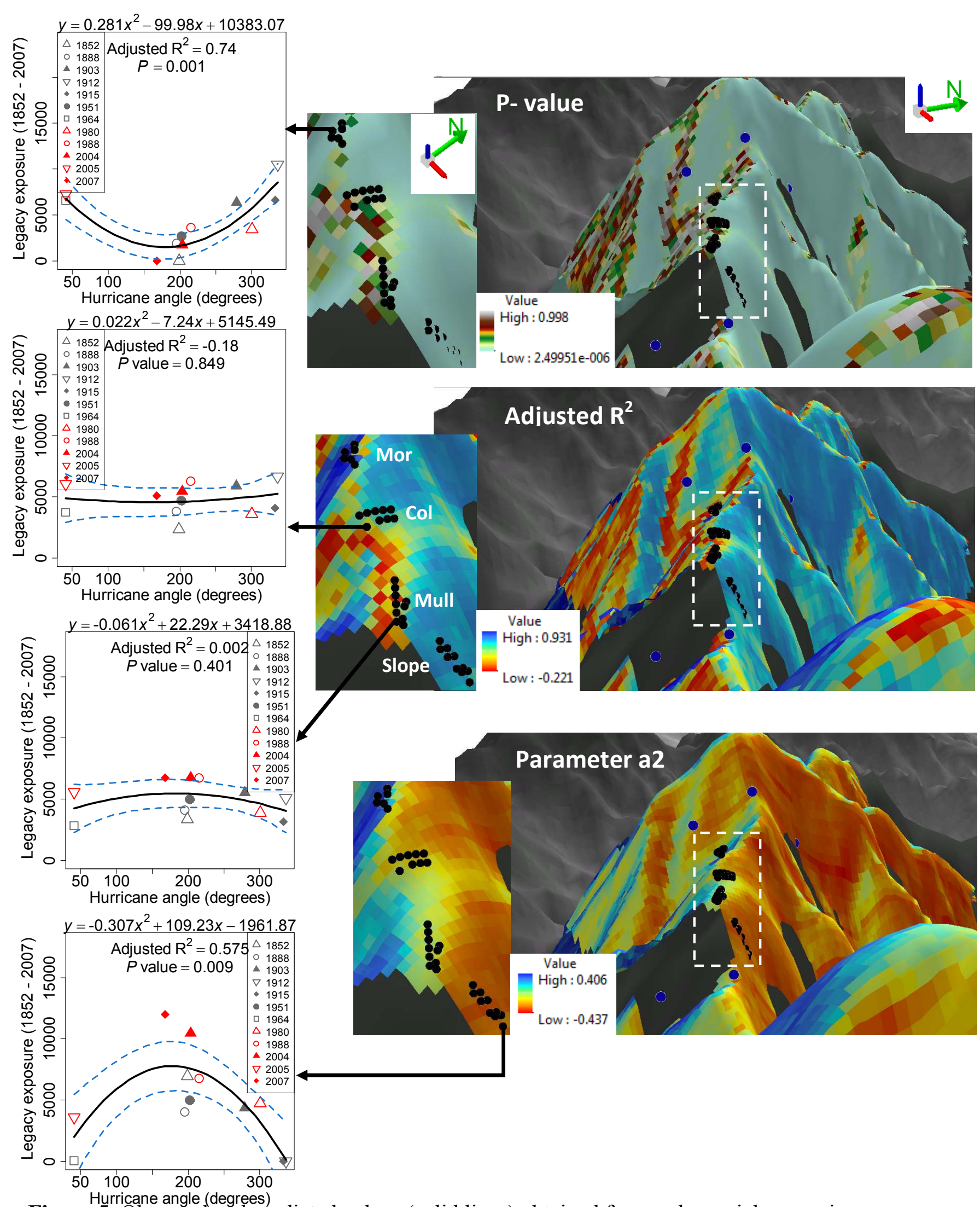

744 Figure 5. Observed and predicted values (solid lines) obtained from polynomial regression

745 models of the relationship between hurricane direction and a time series of exposure

746 vulnerability (for 12 hurricanes during 1852-2007 or Legacy exposure), at several of Tanner's

747 (1977) plot locations (black dots) in the Blue Mountains, Jamaica. Dashed blue lines = standard

748 error. Blue dots in the larger maps = Bellingham et al.'s (1991) plot locations. 

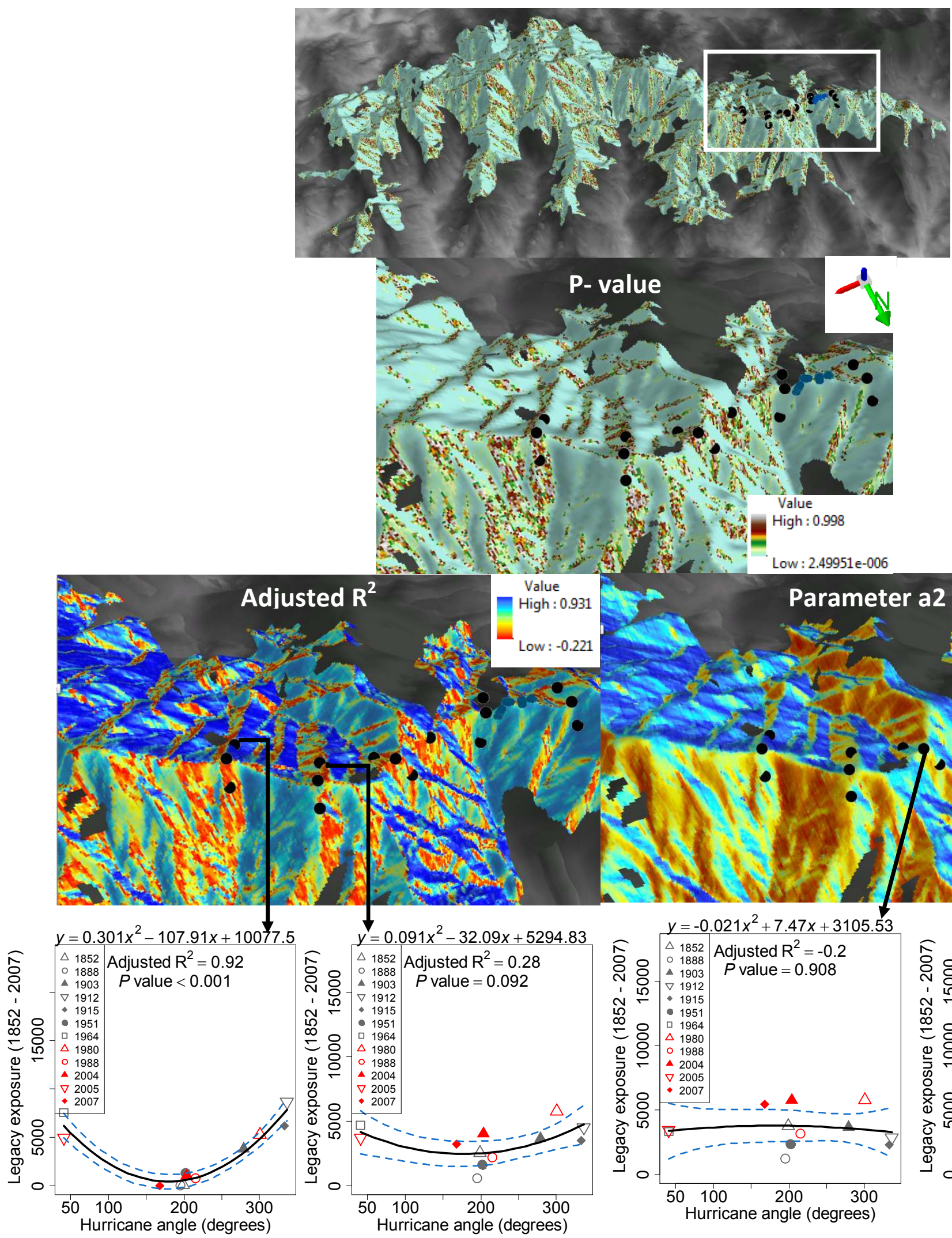

\section{sted $\mathbf{R}^{2}$}



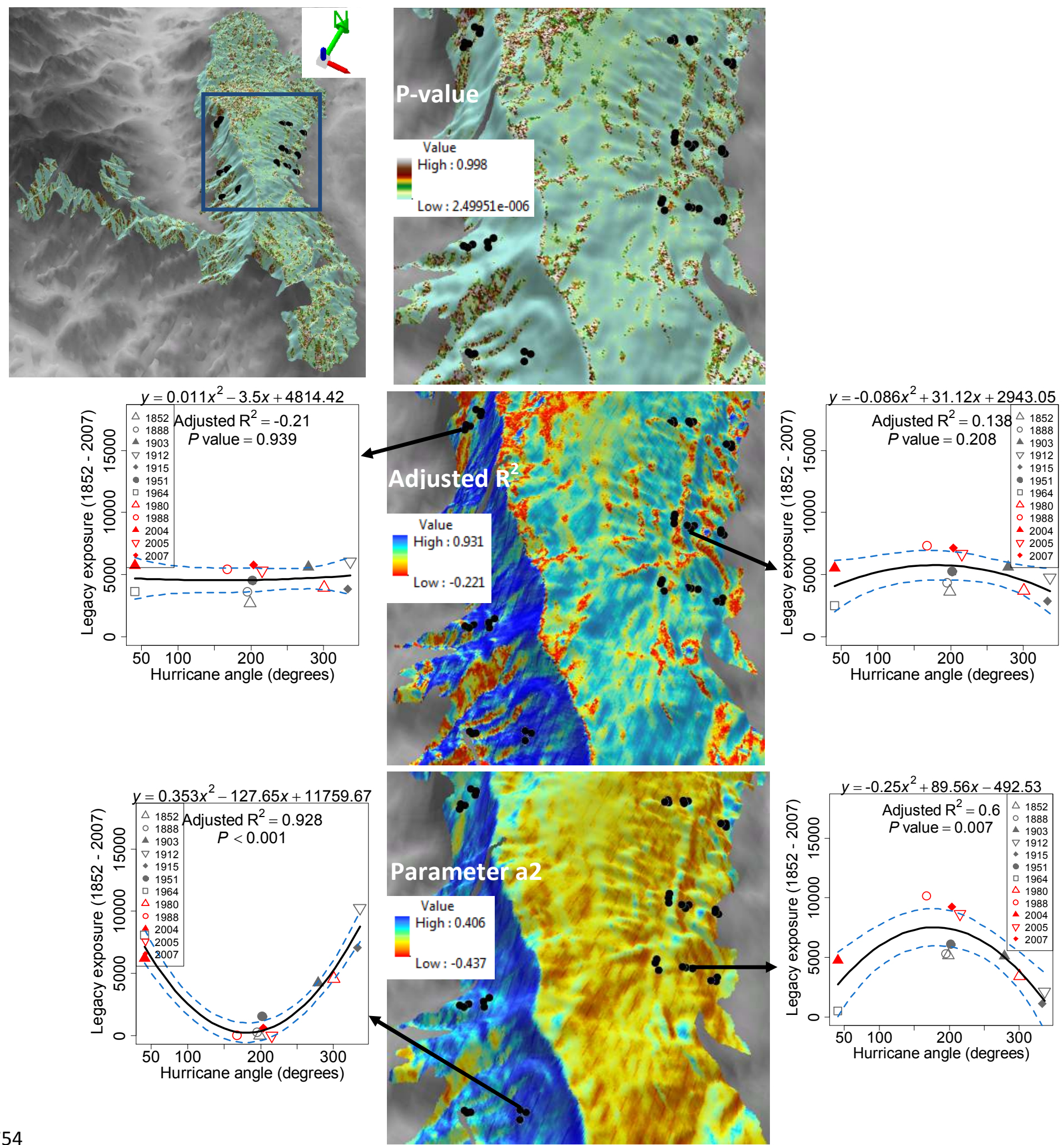

755 Figure 7. Observed and predicted values (solid lines) obtained from polynomial regression

756 models of the relationship between hurricane direction and a time series of exposure

757 vulnerability (for 12 hurricanes during 1852-2007 or Legacy exposure), at several of Luke et

758 al.'s (2016a) plot locations (black dots) in the John Crow Mountains, Jamaica. Dashed blue lines

$759=$ standard error. 


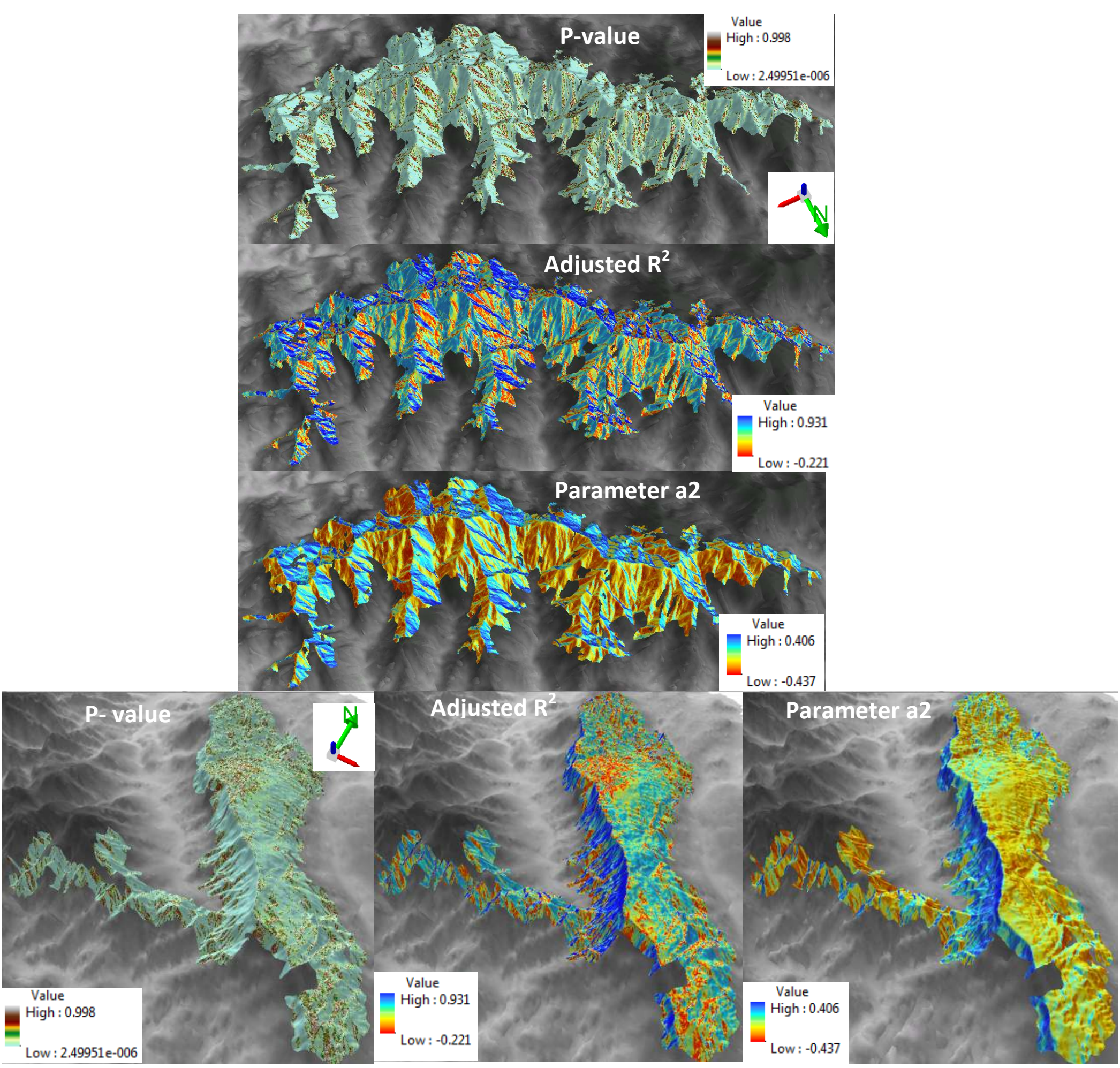

762 Figure 8. Three dimensional views of the outputs from the Curve Fit pixel-level polynomial

763 regression (clipped to the undisturbed forest types in the Blue [top three] and the John Crow

764 [bottom three] Mountains) that was used to assess the influence of average direction (in degrees)

765 of each hurricane at its closest point (independent variable) to the coastline of Jamaica, relative

766 to the center of the Blue and John Crow Mountains, and a time series of exposure vulnerability

767 maps (for 12 hurricanes during 1852-2007 or Legacy exposure) for the Blue Mountains

768 (dependent variable). Value = highest and lowest values for Curve Fit maps. 
769 When the influences of the distance from the eye and the cardinal direction of the track of the

770 eye on the spatial pattern of EV were considered for all hurricanes, the angle or cardinal

771 direction of the track of the eye had a much greater influence on the spatial pattern of EV. In

772 particular, for the Curve Fit P-value cardinal direction map, 78.5\% of the pixels had a value of $P$

$773<0.05$, whereas for the Curve Fit P-value hurricane distance map, only $7.8 \%$ of the pixels had a

774 value of $P<0.05$. Therefore, the distance results were not presented. Angle or cardinal direction

775 of the tracks of the eyes of hurricanes were more important because most of the hurricanes

776 considered in this study either made landfall or passed extremely close to the coast of Jamaica

777 (Figure 1; Table 1). Distance affected the severity of damage caused by the winds, and hence the

778 magnitude of the EV values, but this was dependent on the strength of the winds at the eye and at

779 the outer bands of the hurricanes (Figures 3 and 4; Table 1). If wind speed was very high at the

780 eye and/or at the outer bands, the EV values were usually higher (Figures 3 and 4; Table 1).

781

782 Several outputs from the Curve Fit extension can be used to explain the spatial pattern of long-

783 term EV across the landscape and at the stand-level (Figures 5-8). For example, data extracted

784 from the parameter a2 map can be used to separate EV based on aspect (Figures 5-8). Negative

785 and positive parameter a2 values indicate whether the relationship between EV and the cardinal

786 direction of the hurricane was concave or convex, respectively. This indicated that there was

787 higher EV when the hurricanes passed to the north or south of a site, respectively (Figures 5-8).

788 Negative (concave) and positive (convex) parameter a2 values were almost exclusively found on 789 the northern- and southern- facing slopes, respectively, or on aspects that were more likely to be 790 exposed when a hurricane passed to the north or south of the site, respectively (Figures 5-8).

791 Depending on plot location and the cardinal direction of the tracks of the eyes of hurricanes, 
792 three main patterns of EV can be identified at the stand-level: (1) plots that were highly exposed 793 to all hurricanes irrespective of the cardinal direction of the tracks of the eyes $\left(\mathrm{R}^{2}<0.3\right.$, and $P$ -

794 value $\geq 0.05$ ), (2) plots with an inverted U-shaped (convex) relationship that had significantly

795 higher EVs when the tracks of the eyes of the hurricanes had a southerly cardinal direction (a2 > 796 0), and significantly lower EVs when the of the tracks of the eyes of the hurricanes had more 797 northerly cardinal directions, or (3) plots with a U-shaped (concave) relationship that had 798 significantly lower EVs when the tracks of the eyes of the hurricanes had more southerly 799 cardinal directions $(\mathrm{a} 2<0)$, and significantly higher EVs when the hurricanes had more 800 northerly cardinal directions (Figures 5-7).

801

Modelling stand-level tree diversity and density spatiotemporal patterns

803 Tree Shannon diversity for the period 1974-2009, calculated from Tanner's plot data, was best 804 explained (the most parsimonious model) by average 'legacy' EV for the period 1903-1988 805 (hurricanes in 1903, 1913, 1915, 1951, 1964 and 1988) (Figure 9a; Tables 4 and 5). Hurricane 806 Allen (1980) and hurricanes that affected the site before 1903 and after 1988 were not included 807 in the calculation of legacy EV because they did not improve model fit. Shannon diversity was 808 highest at the lowest and intermediate (where it peaked) legacy EV values, but Shannon diversity 809 was much lower at the highest legacy EV values (Figure 9a). Using data from Bellingham's 810 plots, the best predictor of overall Shannon diversity patterns was the P-value output from the 811 calc function that encompassed 1852-1988 (Figure 9b; Tables 4 and 5). Locations with the 812 lowest P-values, particularly locations with the strongest relationship between EV and the 813 cardinal direction of the track of a hurricane's eye (which were highly exposed when the track 814 passed either to the north or the south of the sites), had the highest Shannon diversity overall; 
815 values decreased as P-values increased and became non-significant (sites that are always exposed

816 to hurricanes, regardless of the angle of the track of eye) (Figure 9b). There were no significant

817 overall relationships between Shannon diversity values and the parameters that were assessed for

818 the JCM using data from Luke et al. (2016a). However, Luke et al. (2016a) found that Shannon

819 diversity values for the 2012 plot data increased as average EV for the three most recent

820 hurricanes (Ivan, Dennis and Dean) increased.

821

822 Tree (stem) density, calculated using data from Tanner's plots, was overall best explained by

823 topographic position index (result not presented here), whereas for Bellingham's plot data, the

824 most important predictor of tree density was the adjusted $\mathrm{R}^{2}$ values (Figures 9c; Tables 4 and 5).

825 For the latter, tree density peaked at sites that were always exposed to hurricanes that affected

826 the site during 1852-1988, regardless of the cardinal direction of their tracks (adjusted $\mathrm{R}^{2}=0.2-$

827 0.4). Tree density in the JCM was highest at more exposed aspects (Luke et al. 2016a).

828 Therefore, the most important predictor of tree density was average legacy EV (1988-2007),

829 with higher tree (stem) densities at higher EVs (Figures 9d; Tables 4 and 5). For the individual

830 censuses of Tanner's plots, the best predictor of Shannon diversity for the census years 1974,

831 1984, 1989, 1991 and 1994 was average (legacy) EV for hurricanes that affected the site over the

832 period 1903-1964 (Figures 9e-i; Table 6). For the year 2009, legacy EV for hurricanes in the

833 period 1915-1988, was the best predictor (Figures 9j; Table 6). The individual censuses reflected

834 the overall diversity pattern, with Shannon diversity being highest at lower and intermediate

835 legacy EV values and lower at the highest values (Figures $9 \mathrm{e}-\mathrm{j}$ ). The marginal $\mathrm{R}^{2}$ increased from

$83633 \%$ in 1974 to $43 \%$ in 1984 , then subsequently decreased in $1989(40.5 \%)$ until $1994(25.6 \%)$

837 (Table 6). It increased again in 2009 (31.8\%). There were no important predictors of Shannon 
2

diversity in 2004. Similarly, for Bellingham's plots, Shannon diversity in 2004 was best explained by legacy EV (hurricanes in the period 1903-1988), with the highest diversity values occurring at intermediate EV values (Figure 9k; Table 6).

Table 4. The best predictors of overall (regardless of census) tree diversity calculated as Shannon-Wiener H' and stem density calculated using data from Tanner's (ET) and Bellingham's (PJB) plots in the Blue Mountains (BM), Jamaica, and stem density from Luke et al.'s plots in the John Crow Mountain (JCM), Jamaica. Important variables included 'legacy' (average) exposure vulnerability to hurricanes during the period 1903-1988 (Exposure), Curve Fit (ET and JCM) and calc (PJB) outputs (P-value, Parameter a2, Adjusted $\mathrm{R}^{2}$ ) and topographic parameters (Aspect).

\begin{tabular}{llclcc}
\hline Site & $\begin{array}{l}\text { Smoother and/or } \\
\text { distribution }\end{array}$ & Variable & Parameters & DIC & mR $^{2}$ \\
\hline BM (ET) & RW1 & H' & Exposure & 23.19 & 25.3 \\
BM (ET) & RW1 & H' & Parameter a2 & 29.36 & 23.2 \\
BM (ET) & RW1 & H' & Adjusted R & 31.87 & 22.9 \\
BM (ET) & RW1 & H' & Aspect & 34.54 & 22.0 \\
\hline BM (PJB) & Gamma & H' & P-value & 22.51 & 32.9 \\
BM (PJB) & RW2 Gamma & H' & Adjusted R $\left.{ }^{2}+(\text { Adjusted R })^{2}\right)^{2}$ & 23.57 & 34.7 \\
BM (PJB) & RW2 Gamma & H' & Exposure & 31.87 & 30.62 \\
\hline BM (PJB) & RW2 Gamma & Density & Adjusted R & -69.2 & 85.1 \\
BM (PJB) & RW2 Gamma & Density & P-value & -54.1 & 79.0 \\
BM (PJB) & Gamma & Density & Exposure & -17 & 40.5 \\
BM (PJB) & RW2 Gamma & Density & Aspect & -10.7 & 37.7 \\
\hline JCM & RW1 Gamma & Density & Exposure & -156.2 & 27.1 \\
JCM & RW1 Gamma & Density & Parameter a2 & -154.7 & 26.6 \\
JCM & Gamma & Density & Aspect & -154.8 & 24.2 \\
JCM & Gamma & Density & Adjusted R & -142.7 & 17.6 \\
\hline
\end{tabular}

$\mathrm{DIC}=$ Deviance Information Criterion; $\mathrm{mR}^{2}=$ marginal R-squared (\%); Gamma = Gamma likelihood; $\mathrm{RW} 1 / \mathrm{RW} 2$ = first or second-order random walk process (smoother).

3

5

(1)



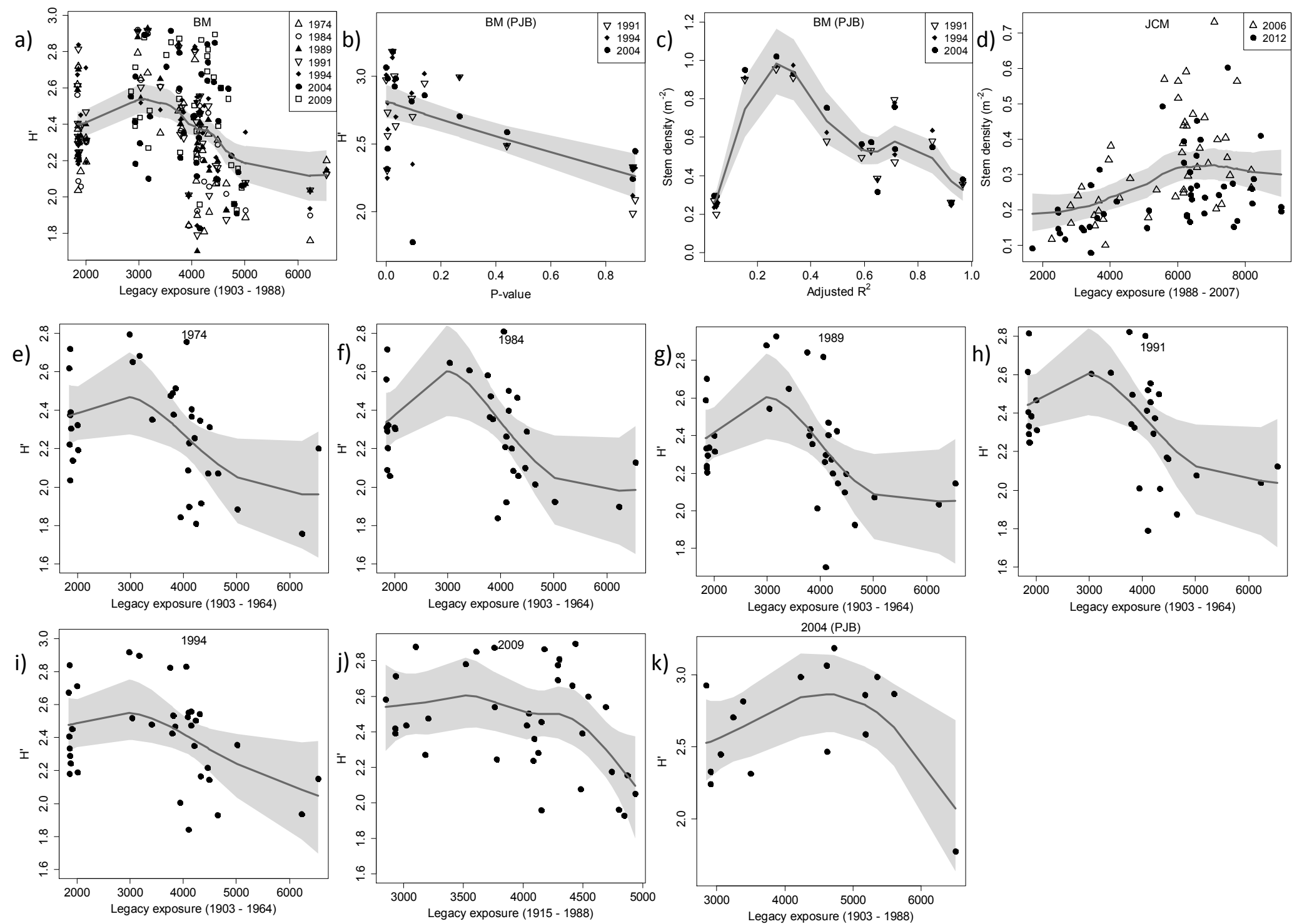

862 Figure 9. Observed and predicted mean values (solid lines) and the 95\% Bayesian credible

863 intervals for the posterior distribution (shade) obtained from hierarchal Bayesian space-time

864 models for the best predictor of overall (regardless of time) a) diversity calculated as Shannon-

865 Wiener diversity index (H') for the Blue Mountains (BM), Jamaica, using data from Tanner's

866 plots, b) H'and c) stem density values for the BM, calculated using data from Bellingham's plots,

867 and d) stem density values for the John Crow Mountains (JCM), Jamaica, calculated using data

868 from Luke et al.'s plots and best predictor of H' values for each census, calculated using data

869 from e-j) Tanner's and k) Bellingham's plots in the BM. Important variables included 'legacy'

870 (average) exposure vulnerability for different periods/years and the calc output (P-Value and

871 Adjusted $\mathrm{R}^{2}$ ).

872

873

874 
Table 5. Summary of the marginal posterior distribution for model parameters obtained from hierarchical INLA Bayesian space-time models for the best predictors of overall (regardless of census) diversity calculated as Shannon-Wiener H' and stem density calculated using data from Tanner's (ET) and Bellingham's (PJB) plots in the Blue Mountains (BM), Jamaica and stem density calculated from Luke et al.'s plots in the John Crow Mountain (JCM), Jamaica. Important variables (95\% credible intervals did not contain zero) included 'legacy' average exposure vulnerability to hurricanes during the periods 1903-1988 for the ET plots and 19882007 for the JCM plots (Exposure) and calc outputs (P-value).

\begin{tabular}{|c|c|c|c|c|c|c|c|}
\hline Site & Variable & Parameters & Mean & $\mathbf{Q}_{0.025}$ & $\mathbf{Q}_{0.975}$ & $\mathbf{m R}^{2}$ & Priors \\
\hline \multirow{6}{*}{$\begin{array}{l}\text { BM } \\
(\mathrm{ET})\end{array}$} & \multirow[t]{2}{*}{ H' } & Intercept & 2.38 & 2.34 & 2.41 & \multirow[t]{6}{*}{25.3} & \\
\hline & & obs.var & 0.062 & 0.051 & 0.076 & & \\
\hline & \multirow[t]{4}{*}{ RW1 } & Exposure.var & 0.003 & 0.001 & 0.006 & & $0.009,0.05$ \\
\hline & & spde.var.nom & 0.000102 & -0.000015 & 0.000683 & & $0.0023,0.5$ \\
\hline & & spde.range.nom & 6.0 & 0.5 & 27.9 & & $3.9,0.5$ \\
\hline & & AR.rho & -0.02 & -0.99 & 0.98 & & \\
\hline \multirow{6}{*}{$\begin{array}{l}\text { BM } \\
(\mathrm{PJB})\end{array}$} & \multirow{6}{*}{$\begin{array}{l}\text { H' } \\
\text { Gamma }\end{array}$} & Intercept & 1.0 & 0.99 & 1.1 & \multirow[t]{6}{*}{32.9} & \\
\hline & & P-value & -0.2 & -0.3 & -0.1 & & \\
\hline & & obs.var & 0.01 & 0.009 & 0.02 & & \\
\hline & & spde.var.nom & 0.00003 & -0.0000004 & 0.0002 & & $0.0023,0.5$ \\
\hline & & spde.range.nom & 4.8 & 0.5 & 19.9 & & $3.9,0.5$ \\
\hline & & AR.rho & 0.004 & -1.0 & 1.0 & & \\
\hline \multirow{6}{*}{$\begin{array}{l}\mathrm{BM} \\
(\mathrm{PJB})\end{array}$} & \multirow{6}{*}{$\begin{array}{l}\text { Density } \\
\text { Gamma } \\
\text { RW2 }\end{array}$} & Intercept & -0.7 & -0.7 & -0.6 & \multirow[t]{6}{*}{85.1} & \\
\hline & & obs.var & 0.04 & 0.03 & 0.07 & & \\
\hline & & Adjusted $\mathrm{R}^{2}$.var & 0.09 & 0.04 & 0.17 & & $0.065,0.05$ \\
\hline & & spde.var.nom & 0.00002 & -0.0000003 & 0.0001 & & $0.0023,0.5$ \\
\hline & & spde.range.nom & 7.9 & 0.7 & 40.1 & & $3.9,0.5$ \\
\hline & & AR.rho & 0.002 & -1.0 & 1.0 & & \\
\hline \multirow[t]{6}{*}{$\mathrm{JCM}$} & \multirow{6}{*}{$\begin{array}{l}\text { Density } \\
\text { Gamma } \\
\text { RW1 }\end{array}$} & Intercept & -1.30 & -1.37 & -1.22 & \multirow[t]{6}{*}{27.1} & \\
\hline & & obs.var & 0.14 & 0.10 & 0.19 & & \\
\hline & & Exposure.var & 0.009 & 0.003 & 0.021 & & $0.03,0.05$ \\
\hline & & spde.var.nom & 0.0000232 & -0.0000009 & 0.0001545 & & $0.002,0.5$ \\
\hline & & spde.range.nom & 6.4 & 0.7 & 29.9 & & $4,0.5$ \\
\hline & & AR.rho & -0.002 & -0.988 & 0.988 & & \\
\hline
\end{tabular}

884

885

886

887

888

889

890

891

892

893

894
$\mathrm{Q}_{0.025}$ and $\mathrm{Q}_{0.975}=$ quantiles of the credible interval; DIC $=$ Deviance Information Criterion; $\mathrm{mR}^{2}=$ marginal R-squared (\%);Gamma = Gamma likelihood; RW1/RW2 = first or second-order random walk process (predictor variance is followed by .var, e.g., Exposure.var for RW1 and Prior $=$ reference standard deviation and the right tail probability); obs.var = model variance; spde.var.nom $=$ nominal spatial variance $($ Priors $=$ prior marginal standard deviation and right tail probability); spde.range.nom $=$ nominal spatial range $(\mathrm{km})($ Priors $=$ practical range and right tail probability); AR.rho $=$ autoregressive parameter, temporal correlation coefficient. 
895 Table 6. Summary of the marginal posterior distribution for model parameters obtained from 896 hierarchical INLA Bayesian space-time models for the best predictors of diversity calculated as 897 Shannon-Wiener H-Index from Tanner's (ET) and Bellingham's (PB) plots in the Blue 898 Mountains, Jamaica, for each census. Average exposure vulnerability (Expos) to hurricanes 899 during the period 1903-1988 was the most important variable (95\% credible intervals did not 900 contain zero).

\begin{tabular}{|c|c|c|c|c|c|c|c|}
\hline Site & Variable & Parameters & Mean & $\mathbf{Q}_{0.025}$ & $Q_{0.975}$ & $\mathbf{m R}^{2}$ & Priors \\
\hline $\mathrm{BM}$ & $\mathrm{H}^{\prime}$ & Intercept & 2.28 & 2.20 & 2.37 & \multirow[t]{5}{*}{33} & \\
\hline \multirow[t]{4}{*}{ ET } & 1974 & obs.var & 0.06 & 0.03 & 0.10 & & \\
\hline & \multirow{3}{*}{ RW2 } & Expos (1903 -1964).var & 0.0732 & 0.0005 & 0.3326 & & $0.3,0.05$ \\
\hline & & spde.var.nom & 0.0000234 & -0.0000003 & 0.0001544 & & $0.0023,0.5$ \\
\hline & & spde.range.nom & 7.3 & 0.7 & 35.6 & & $3.9,0.5$ \\
\hline $\mathrm{BM}$ & $\mathrm{H}^{\prime}$ & Intercept & 2.32 & 2.24 & 2.40 & \multirow[t]{5}{*}{43} & \\
\hline \multirow[t]{4}{*}{ ET } & 1984 & obs.var & 0.05 & 0.03 & 0.08 & & \\
\hline & RW2 & Expos (1903-1964).var & 0.114 & 0.010 & 0.380 & & $0.3,0.05$ \\
\hline & & spde.var.nom & 0.0000194 & -0.0000004 & 0.0001249 & & $0.0023,0.5$ \\
\hline & & spde.range.nom & 8.1 & 0.7 & 40.8 & & $3.9,0.5$ \\
\hline $\mathrm{BM}$ & $\mathrm{H}^{\prime}$ & Intercept & 2.35 & 2.27 & 2.43 & \multirow[t]{5}{*}{40.5} & \\
\hline \multirow[t]{4}{*}{ ET } & 1989 & obs.var & 0.05 & 0.03 & 0.08 & & \\
\hline & RW2 & Expos (1903-1964).var & 0.101 & 0.007 & 0.345 & & $0.3,0.05$ \\
\hline & & spde.var.nom & 0.0000183 & -0.0000004 & 0.0001159 & & $0.0023,0.5$ \\
\hline & & spde.range.nom & 7.9 & 0.7 & 39.7 & & $3.9,0.5$ \\
\hline $\mathrm{BM}$ & $\mathrm{H}^{\prime}$ & Intercept & 2.38 & 2.30 & 2.46 & \multirow[t]{5}{*}{37.9} & \\
\hline \multirow[t]{4}{*}{ ET } & 1991 & obs.var & 0.05 & 0.03 & 0.09 & & \\
\hline & RW2 & Expos (1903 -1964).var & 0.0749 & 0.0023 & 0.2896 & & $0.3,0.05$ \\
\hline & & spde.var.nom & 0.0000181 & -0.0000004 & 0.0001139 & & $0.0023,0.5$ \\
\hline & & spde.range.nom & 8.2 & 0.8 & 41.8 & & $3.9,0.5$ \\
\hline $\mathrm{BM}$ & $\mathrm{H}^{\prime}$ & Intercept & 2.41 & 2.33 & 2.50 & \multirow[t]{5}{*}{25.6} & \\
\hline \multirow[t]{4}{*}{ ET } & 1994 & obs.var & 0.06 & 0.04 & 0.10 & & \\
\hline & RW2 & Expos (1903 -1964).var & 0.0479 & 0.0003 & 0.4525 & & $0.3,0.05$ \\
\hline & & spde.var.nom & 0.0000192 & -0.0000004 & 0.0001230 & & $0.0023,0.5$ \\
\hline & & spde.range.nom & 8.1 & 0.7 & 41.0 & & $3.9,0.5$ \\
\hline $\mathrm{BM}$ & $\mathrm{H}^{\prime}$ & Intercept & 2.46 & 2.38 & 2.55 & \multirow[t]{5}{*}{31.8} & \\
\hline \multirow[t]{4}{*}{ ET } & 2009 & obs.var & 0.06 & 0.04 & 0.10 & & \\
\hline & RW2 & Expos (1915 -1988).var & 0.0414 & 0.0002 & 0.4477 & & $0.3,0.05$ \\
\hline & & spde.var.nom & 0.0000300 & -0.0000005 & 0.0002044 & & $0.0023,0.5$ \\
\hline & & spde.range.nom & 5.1 & 0.6 & 21.9 & & $3.9,0.5$ \\
\hline $\mathrm{BM}$ & $\mathrm{H}^{\prime}$ & Intercept & 0.98 & 0.92 & 1.04 & \multirow[t]{5}{*}{51.1} & \\
\hline \multirow[t]{4}{*}{$\mathrm{PB}$} & 2009 & obs.var & 0.013 & 0.006 & 0.027 & & \\
\hline & RW2 & Expos (1903 -1988).var & 0.0024 & 0.0003 & 0.0083 & & $0.05,0.05$ \\
\hline & & spde.var.nom & 0.0000185 & -0.0000004 & 0.0001167 & & $0.0023,0.5$ \\
\hline & & spde.range.nom & 8.2 & 0.8 & 41.3 & & $3.9,0.5$ \\
\hline
\end{tabular}

$901 \mathrm{Q}_{0.025}$ and $\mathrm{Q}_{0.975}=$ quantiles of the credible interval; $\mathrm{mR}^{2}=$ marginal R-squared (\%); RW2 = random

902 second-order random walk process (predictor variance is followed by .var, e.g., Expos.var for RW2 and

903 Prior $=$ reference standard deviation and the right tail probability); Gamma $=$ Gamma likelihood; obs.var

$904=$ model variance; spde.var.nom $=$ nominal spatial variance $($ Priors $=$ prior marginal standard deviation 
905

906

907

908

909

910

911

912

913

914

915

916

917

918

919

920

921

922

923

924

925

926

927

928

and right tail probability); spde.range.nom $=$ nominal spatial range $(\mathrm{km})($ Priors $=$ practical range and right tail probability); AR.rho = autoregressive parameter, temporal correlation coefficient.

\section{Discussion}

\section{Topographic exposure in the Blue and John Crow Mountains}

Topographic exposure models are generally used to identify points on a landscape-scale topographic surface that are protected from (wind shadow) or exposed to specific wind directions (Boose et al. 1994). The wind shadow is estimated by assuming that the wind bends downwards at a fixed inflection angle from the horizontal as it passes over an elevated surface (Boose et al. 1994). It does not however, estimate changes in wind speed or direction caused by local topography (Boose et al. 1994). In addition, exposure models do not consider the movement of wind over complex terrain and meteorological conditions usually found near the center of a hurricane such as steep gradients of pressure velocity, local convective cells and curved wind paths and rain bands (Boose et al. 1994). Also, exposure models do not consider changes or alterations in these gradients at fixed locations due to a storm's forward movement, intensification or weakening (Boose et al. 1994). These complexities are difficult and problematic to model (Boose et al. 1994).

The simple topographic exposure model used in our study therefore lacks complexity, nevertheless, exposure models work at landscape scales $(\approx 10 \mathrm{~km})$ and provide useful predictions of areas protected from or exposed to damaging winds (Boose et al.1994). Also, reconstructed landscape-level exposure maps are generally tested by comparing predicted exposure to actual landscape-level (Boose et al. 1994) or stand-level damage (e.g. Batke et al. 2014; Negrón-Juárez et al. 2014a and 2014b; Luke et al. 2016a) to determine if they can be used as proxies for 
929 hurricane damage. Stand-level damage data are generally collected within 2 years within after a 930 disturbance event, although stand-level damage data have been collected up to 12 years after a

931 hurricane stuck (Gannon and Martin 2014). In our study, the reconstructed exposure maps for

932 Hurricane Gilbert were tested or evaluated using stand-level damage and recovery data from

933 Bellingham's plots, which were collected 20-23 months after that hurricane struck the BM.

934 Bellingham's plots included locations with a wider range of topographic positions (Bellingham 935 and Tanner 2000) (Figure 7) and were more suitable for the EV model evaluation than those of

936 Tanner. Tanner's plots varied more in topographic position than in EV due to the location of the

937 plots in nearby blocks located in strongly contrasting topographic positions (Figure 7). As such,

938 Bellingham's plot data showed a stronger relationship of damage and recovery to EV and have

939 greater general validity/power for this analysis than do Tanner's plot data (Figure 2; Tables 2 and

940 3). The method presented in this study can therefore be used to reconstruct past hurricane

941 (legacy) EV, which can be used as a proxy for landscape-scale hurricane disturbance/damage at 942 un-sampled locations and for hurricanes for which no disturbance data are available. We found

943 that if less ideal proxies were used, at the very least they could be used to produce landscape-

944 level maps that summarize the extent of forest recovery.

945

946 At the landscape scale, the spatial pattern of hurricane exposure that was reported in this study 947 was consistent other published observations. In the southern hemisphere, disturbance severity is 948 usually greater on the left side of a cyclone's path due to clockwise rotation of cyclone winds. 949 For example, large areas of undisturbed forest were found on the right side of the track of 950 tropical cyclone Yasi after it struck the northeastern rainforests of Queensland, Australia 951 (Negrón-Juárez et al. 2014a and 2014b). In contrast, in the northern hemisphere (US Gulf Coast 
952 forest ecosystems), forest disturbance severity was observed to be greater on the right side of the 953 tracks of four hurricanes (Negrón-Juárez et al. 2014a) due to counter-clockwise rotation of 954 cyclone winds. Additionally, in central new England, USA, the most destructive winds of a 1938

955 hurricane occurred to the east (right) of the eye where the highest wind speeds were produced 956 from the anticlockwise rotary velocity and forward movement (Foster, 1988). In addition, 957 damage was lower to the west (left) of the eye where wind speeds were lower (Foster, 1988). 958 These observations were consistent with those of Boose et al. (1994), who found that as 959 Hurricane Hugo approached the Luquillo Experiment Forest (LEF), Puerto Rico, from the east, 960 with a track that was initially oriented to the south of the site, the strongest winds associated with 961 the leading eye wall were to the northeast (to the right). At the same site, after $\approx 2 \mathrm{hrs,} \mathrm{the}$ 962 trailing eyewall winds were weaker and were from the SSW (Boose et al. 1994). As a result, the 963 north-facing slopes of the LEF were more exposed and the southern slopes, facing the weaker 964 trailing eyewall winds from the SW and SSW, were less exposed (Boose et al. 1994) and showed 965 little damage (Scatena and Larsen 1991). Similarly, after tropical cyclone Yasi struck the 966 northeastern rainforests of Queensland, forest disturbance was found to be higher at aspects that 967 were facing away from the dominant surface winds (Negrón-Juárez et al. 2014b).

969 In our study, the orientation of the tracks of the eye or center of the hurricanes, even if they made 970 landfall, passed either to the north or south of the study sites and this influenced the pattern of 971 exposure (Figures 4-8). We found that when the eye of a hurricane followed a path or track with 972 a southern orientation, the pattern of exposure was similar to other reported observations; that is, 973 the right side of the track (the north-eastern to south-eastern aspects) were more exposed 974 (Figures 4-8). However, when the eye followed a northern orientation, wind bands from the 
975 leading eye wall were mostly offshore, and it was the wind bands from the trailing eye wall that 976 passed over the sites, resulting in greater exposure on the left side of the track (the southern to 977 south-western aspects) (Figures 4-8). Furthermore, there were equal numbers of hurricanes (six 978 each) that followed a path north or south of the sites, and multiple hurricanes followed a similar 979 path in relatively quick succession (Figures 1, 3 and 4). For example, two hurricanes, in 1852 980 and 1889, had tracks to the south of Jamaica and three hurricanes that made landfall over a 981 period of 12 years (1903, 1912 and 1915) had northerly tracks (Figures 1, 3 and 4). Also, four 982 hurricanes made landfall over a period of 48 years (1903-1951) or followed a track to the north 983 of the island in 61 years (1903-1964) (Figures 1, 3 and 4). Since 1988, most hurricanes followed 984 a track to the south (four in 19 years), although only one made landfall (Gilbert) (Figures 1, 3

985 and 4). Therefore, since 1852, most aspects at the two sites have been exposed to multiple 986 hurricanes, with only locations with a north-western aspect being severely exposed to only a

987 single hurricane (Allen in 1980) (Figure 4). At the two study sites (both on steeply-sloped 988 mountain ranges), exposure, hence disturbance history at the stand- level, was a function of angle 989 or cardinal direction of both hurricane tracks and local topography (Figures 5-8). As a result, the 990 stand-level assessments of hurricane impacts in the BM and JCM were strongly influenced by 991 plot location. Some plots, despite being located close to each other, had a different disturbance

992 history or degree of exposure (Bellingham et al. 1991), while the disturbance history and 993 exposure was similar for some plots that were located far away from each other (Figures 5-7).

\section{The impact of legacy hurricanes on stand-level spatiotemporal diversity and density patterns}

996 Advances in historical hurricane damage modelling create opportunities for improving estimates

997 of hurricane impacts (Logan and $\mathrm{Xu}$ 2015). Models can now account for temporal correlation 
and spatial dependence simultaneously (Logan and $\mathrm{Xu} 2015)$. Therefore, these models can be used (and were used in this study to evaluate 1) whether individual hurricanes had effects, 2) whether it was only the most severe hurricanes that made a difference, 3 ) whether it was the cumulative effect of several hurricanes over many years that was more important and 4) whether 1002 the hurricane effects were temporary or prolonged (Logan and Xu 2015). For the BM, there was 1003 an increase in tree diversity at the stand-level in the decades following the passage of Hurricane 1004 Gilbert (Tanner and Bellingham 2006). However, diversity also increased during the pre-Gilbert 1005 census period and there were mostly light-demanding species present in the canopy in 1974 1006 (Tanner and Bellingham 2006), possibly due to the effects of previous disturbances, including 1007 hurricanes. Also, five hurricanes struck in 61 years (1903-1964), four of which made landfall 1008 over a period of 48 years (1903-1951), and the eyes or centers of four hurricanes followed a 1009 more northerly track (Figures 1, 3 and 4). The BM were therefore exposed to frequent high1010 intensity hurricanes and, as such, the heterogeneity of disturbance caused by, for example, the 10111903 hurricane may have been maintained for an extended period ( 85 years) by successive 1012 hurricanes (Figure 4). This may have permitted greater species co-existence at sites with 1013 intermediate exposure and an increase in diversity to occur over time, even after Hurricane 1014 Gilbert affected the BM. As a result, the influence of legacy EV on the pattern of diversity, that 1015 is peak diversity at intermediate exposures, was similar overall (regardless of time) (Figure 9a) 1016 and for the individual censuses of both Tanner's and Bellingham's plots (Figures 9e-k). This is 1017 despite the two sets of plots differing in the number, size, shape and layout or design. However, 1018 for Bellingham's plots, the effects of past disturbance were manifest in a different way. In 1019 particular, the magnitude of exposure resulting from the cardinal direction or orientation of the 1020 hurricane's eye or center (P-value from the calc function) was the most important predictor of 
1021 tree Shannon diversity and density in Bellingham's plots (Figure 9b). That is, tree diversity was

1022 highest at plot locations that were more likely to be exposed when a hurricane's eye followed a

1023 track that was either to the north or to the south of the sites, and lowest at sites that were highly

1024 exposed to all hurricanes. In contrast, tree density peaked at sites that were always exposed,

1025 regardless of the cardinal direction of the center of the hurricanes (Figure 9c). Both patterns, with

1026 that for diversity also being found for the clustered Tanner plots, agree with the two hypotheses,

1027 i.e. tree diversity was highest at sites subject to intermediate levels of disturbance but tree density

1028 was greatest at sites subject to the highest levels of disturbance. Differences between the two

1029 data sets in terms of the importance of predictors of exposure may be due to plot location.

1030 Tanner's plots were purposefully located in four clusters each placed in a contrasting forest type

1031 that occurred in close proximity (Tanner 1977), whereas Bellingham's plots were located in a

1032 more dispersed sampling design stratified between three topographic positions (Bellingham

1033 1991) (Figures 5 and 6).

1034

1035 The results from the individual census assessments can be used to determine when the effects of

1036 a hurricane on tree diversity and density became important or for how long their effects lasted.

1037 Average legacy exposure of five hurricanes occurring during 1903-1964 was the most important

1038 predictor of diversity in Tanner's plots in 1974, and this effect lasted until 1994 or 91 years

1039 (Figures 9e-i). Exposure vulnerability to Hurricane Gilbert was not important in these plots

1040 (because it did not improve model fit) until 21 years after the hurricane affected the plots (Figure

1041 9j). For Bellingham's plots, average 1903-1988 legacy exposure, which included the EV for

1042 Hurricane Gilbert, was important in 2004, 16 years after Gilbert struck, and the 1903 hurricane

1043 was still important 101 years after it struck (Figure 9k). In comparison, the effects of three 
1044 successive hurricanes that made landfall (in 1928, 1931 and 1932) on forest structure and

1045 composition in the Luquillo Experimental Forest, Puerto Rico, lasted for nearly 50 years after the

1046 last hurricane (Weaver 2002). Moreover, stand-level spatiotemporal patterns in tree diversity in

1047 the BM plots are likely to have been most influenced by the hurricanes that made landfall, with

1048 their highest wind speeds closest to the study sites. With the exception of Hurricane Cleo in

1049 1964, all other hurricanes that passed Jamaica at some distance off the coast had little or no

1050 influence.

1051

1052 Although the BM and JCM had a similar disturbance history, the effects of hurricane disturbance

1053 were manifest in different ways. In particular, we found that forest type influenced the

1054 heterogeneity of forest damage across a landscape (Zimmerman et al. 1994; Everham and

1055 Brokaw 1996; Boose et al. 2004). The ridge-top forest of the BM was found to be the least

1056 damaged (the least crown breakage and little tree uprooting) of four Jamaican forests that were

1057 assessed 3-8 months following the passage of Hurricane Gilbert (Bellingham et al. 1992). This

1058 was attributed to greater resistance of the ridge-top forest to winds, due to a more streamlined,

1059 aerodynamic and even canopy, because of its exposed topographic position (Bellingham et al.

1060 1992). Also, there had presumably been a strong selection for tree species and/or structural

1061 characteristics (shorter canopy and greater ratio of stem width to height (Lawton 1982)) with

1062 greater resistance to strong winds (Bellingham et al. 1992). In contrast, trees in the lower

1063 montane forest of the JCM were found to be more susceptible to uprooting than at the other sites

1064 due to the greater impact of Hurricane Gilbert on this site, the greater average height of trees, and

1065 poor anchoring of trees due to the limestone substrate (Bellingham et al. 1992). The JCM may

1066 have also been more affected than the BM by the outer bands of the last three hurricanes that 
1067 passed 40-45 $\mathrm{km}$ from the island (Figures 3 and 4). There were obvious signs of hurricane

1068 damage in the JCM after Hurricanes Ivan and Dennis struck (pers. obs.), and eight months after

1069 Hurricane Dean, in 2004, 2005 and 2007, respectively (Luke et al. 2016a), but no obvious

1070 evidence of damage or disturbance was found in the BM plots during the 2009 census (Tanner et

1071 al. 2014). As a result, EV from these hurricanes was not an important predictor of spatial

1072 variation in tree density and/or diversity in the BM (or the effects take longer to become

1073 manifest). Individual hurricane EV, or the average EV for the last three hurricanes, was however

1074 an important predictor of stand-level data from the JCM, in particular individual tree and

1075 community structural changes in 2012, diversity patterns in 2012, and density patterns in 2006

1076 and 2016 (Luke et al. 2016a), and across both censuses of the plots (2006 and 2012). However,

1077 individual hurricane EV or the average over past hurricanes could not be used to explain the

10782006 stand-level diversity patterns. Species composition of the JCM plots may have either

1079 recovered by 2006, after the JCM was struck by Hurricane Gilbert in 1988, or the impact of

1080 Hurricanes Ivan and Dennis may have masked the effects of Gilbert and other past hurricanes.

1082 The rate of turnover of tree stems and species is another potential explanation for the differences

1083 between the BM and JCM. Low turnover rates can be equated to greater resistance to hurricane

1084 damage (Tanner and Bellingham 2006). After Hurricane Gilbert, turnover of tree stems for the

1085 period 1990-1994 was 2.6\% $\mathrm{yr}^{-1}$ for Bellingham's plot data (Bellingham and Tanner 2000), and

$10864.06 \% \mathrm{yr}^{-1}$ for the period 1989-1994 and 1.6\% $\mathrm{yr}^{-1}$ for the period 2004-2009 for Tanner's plot

1087 data (Tanner and Bellingham 2006). In comparison, over the period 2006-2012, turnover was

$10882.9 \% \mathrm{yr}^{-1}$, for trees in the JCM following Hurricanes Ivan, Dennis and Dean (Luke et al.

1089 2016a,b). As such, turnover at the stand-level for the JCM was within the range of values for the 
1090 BM after Gilbert made landfall, but higher than the BM during a period that overlapped, when

1091 three hurricanes passed closed to the island. Additionally, $25-50 \%$ of trees $2-10 \mathrm{~cm}$ in DBH died

1092 during the period 2006-2012 in the JCM (Luke et al. 2016b), likely removing some of the trees

1093 recruited since Hurricane Gilbert (and before). Moreover, in the BM, the mortality of damaged

1094 trees was 2-8 times higher than undamaged stems 19 years after Gilbert (Tanner et al. 2014).

1095 Therefore, the greater resistance and recovery of trees in the BM may have resulted in a delayed 1096 response that was manifest over a longer time. As such, the influence of Gilbert was not evident

1097 until 2004 and 2009 for tree diversity in Bellingham's and Tanner's plots, respectively, and the

1098 influence of several hurricanes was evident for long periods. In contrast, rapid changes in the

1099 JCM due to the impacts of the rapid succession of hurricanes during 2004-2007 may have

1100 removed any signs of the influence of past hurricanes. The rate of turnover of tree stems and 1101 species at the two sites were different and therefore, the effects of hurricane disturbance were 1102 manifest in different ways.

\section{Conclusion}

1105 We developed and validated a method to reconstruct and map landscape scale $\left(\approx 10 \mathrm{~km}^{2}\right)$

1106 exposure to 12 high-intensity hurricanes (category 2-4), which affected the forests of the BM

1107 and JCM in Jamaica, over the past 155 years. The maps were then aggregated and used to

1108 identify the spatial patterns of hurricane exposure and to determine if exposure could be used to

1109 explain current stand-level $\left(\approx 1 \mathrm{~km}^{2}\right)$ tree diversity and density patterns. Exposure variability at

1110 the landscape and local scales was best explained by the orientation or angle of the eye or center

1111 of the hurricane relative to the coastline of Jamaica. This was used to identify three patterns of

1112 historical exposure: exposure was significantly higher to the south or north of a hurricane's track 
1113 when the track was to the north or south of the island/sites, respectively. In the BM, the pattern

1114 of exposure determined by the cardinal direction of all hurricane tracks or exposure to six

1115 hurricanes (over the period 1903-1988), five of which made landfall, was the best predictor of

1116 stand-level spatiotemporal patterns of diversity and density. In particular, there was co-existence

1117 of a greater number of species at sites with intermediate exposure (sensu the intermediate

1118 disturbance hypothesis) and the highest densities were found at sites that were always highly

1119 exposed. In the JCM, stand-level spatiotemporal variation in overall tree density (highest where

1120 exposure was highest) was explained by four of the most recent hurricanes, three of which did

1121 not make landfall. The difference in predictors between the two sites can be explained by forest

1122 type. The ridge top forest in the BM had a greater resistance to hurricane effects, as tree diversity

1123 and density were only influenced by the hurricanes that made landfall. The forest of the JCM had

1124 a lower resistance and, as such, the influence of past hurricanes was reduced by the impact of

1125 three or four of the most recent hurricanes, due to a high turnover of stems and species in the

1126 JCM over a short period of time. The reconstructed landscape-scale maps can therefore be used

1127 to provide valuable insights into the effects of past hurricanes on contemporary patterns of tree

1128 diversity and density at the stand-level $\left(\approx 1 \mathrm{~km}^{2}\right)$ in different forest types.

\section{Acknowledgements}

1131 We thank Ms Rochelle Hollingsworth and Ms Rose-Marie Rochester from Mico University

1132 College, Jamaica, who assisted with generating the exposure maps during their field-based work-

1133 experience tenure (Industry Based Component of the Practicum for their BSc degrees) and their

1134 advisor Dr Lisa Caleb, who organized their programme. In addition, Drs Haakon Bakka and

1135 James Gibbons provided statistical advice. 
1137 References

1138 Banerjee, S., A. E. Gelfand, A. O. Finley, and H. Sang. 2008. Gaussian predictive process

1139 models for large spatial data sets. Journal of the Royal Statistical Society: Series B (Statistical

1140 Methodology) 70: 825-848.

1141

1142 Batke, S. P., M. Jocque, and D. L. Kelly. 2014. Modelling hurricane exposure and wind speed on

1143 a mesoclimate scale: a case study from Cusuco NP, Honduras. PloS One 9: e91306.

1144

1145 Bellingham, P. J. 1991. Landforms influence patterns of hurricane damage: evidence from

1146 Jamaican montane forests. Biotropica 23: 427-433.

1147

1148 Bellingham, P. J. 2008. Cyclone effects on Australian rain forests: An overview. Austral

1149 Ecology 33: 580-584.

1150

1151 Bellingham, P. J., and E. V. J. Tanner. 2000. The influence of topography on tree growth, 1152 mortality, and recruitment in a tropical montane forest. Biotropica 32: 378-384.

1153

1154 Bellingham, P. J., E. V. J. Tanner, and J. R. Healey. 1995. Damage and responsiveness of 1155 Jamaican montane tree species after disturbance by a hurricane. Ecology 76: 2562-2580. 1156 
1157 Bellingham, P. J., V. Kapos, N. Varty, J. R. Healey, E. V. J. Tanner, D. L. Kelly, J. W. Dalling, 1158 L. S. Burns, D. Lee, and G. Sidrak. 1992. Hurricanes need not cause high mortality: the effects 1159 of Hurricane Gilbert on forests in Jamaica. Journal of Tropical Ecology 8: 217-223

1160

1161 Bender, M. A., T. R. Knutson, R. E. Tuleya, J. J. Sirutis, G. A. Vecchi, S. T. Garner, and I. M. 1162 Held. 2010. Modeled impact of anthropogenic warming on the frequency of intense Atlantic 1163 hurricanes. Science 327: 454-458.

1164

1165 Blangiardo, M., and M. Cameletti. 2015. Spatial and spatio-temporal Bayesian models with R1166 INLA. John Wiley \& Sons.

1167

1168 Boose, E. R., D. R. Foster, and M. Fluet. 1994. Hurricane impacts to tropical and temperate 1169 forest landscapes. Ecological Monographs 64: 369-400.

1170

1171 Boose, E. R., M. I. Serrano, and D. R. Foster. 2004. Landscape and regional impacts of 1172 hurricanes in Puerto Rico. Ecological Monographs 74: 335-352.

1173

1174 Cameletti, M., F. Lindgren, D. Simpson, and H. Rue. 2013. Spatio-temporal modeling of 1175 particulate matter concentration through the SPDE approach. AStA Advances in Statistical 1176 Analysis 97: 109-131.

1177

1178 Carslaw, D. C. and K. Ropkins. 2012. openair --- an R package for air quality data analysis. 1179 Environmental Modelling \& Software 27-28: 52-61. 
1181 Chai, S. L., J. R. Healey, and E. V. J. Tanner. 2012. Evaluation of forest recovery over time and 1182 space using permanent plots monitored over 30 years in a Jamaican montane rain forest. PLoS 1183 One 7: e48859.

1184

1185 Connell, J. H. 1978. Diversity in tropical rain forests and coral reefs. Science 199: 1302-1310.

1186

1187 Cosandey-Godin, A., E. T. Krainski, B. Worm, and J. M. Flemming. 2014. Applying Bayesian 1188 spatiotemporal models to fisheries bycatch in the Canadian Arctic. Canadian Journal of Fisheries 1189 and Aquatic Sciences 72: 186-197.

1191 Crawley, M. J. 2012. The R book. John Wiley \& Sons.

1193 Dawid, A. P. 1984. Present position and potential developments: Some personal views:

1194 Statistical theory: The prequential approach. Journal of the Royal Statistical Society. Series A

1195 (General) 147: 278-292.

1196

1197 De Jager, N. R., and T. J. Fox. 2013. Curve Fit: a pixel-level raster regression tool for mapping 1198 spatial patterns. Methods in Ecology and Evolution 4: 789-792.

1200 Denslow, J. S. 1995. Disturbance and diversity in tropical rain forests: the density 1201 effect. Ecological Applications 5: 962-968. 
1203 Early, D. S., and D. G. Long. 2001. Image reconstruction and enhanced resolution imaging from 1204 irregular samples. IEEE Transactions on Geoscience and Remote Sensing 39: 291-302.

1205

1206 Elsner, J. B., J. P Kossin, and T. H. Jagger. 2008. The increasing intensity of the strongest 1207 tropical cyclones. Nature 455: 92-95.

1208

1209 Everham, E. M., III, and N. V. L. Brokaw. 1996. Forest damage and recovery from catastrophic 1210 wind. Botanical Review 62: 113-185.

1211

1212 Foster, D. R. 1988. Species and stand response to catastrophic wind in central New England, 1213 USA. Journal of Ecology 76: 135-151.

1214

1215 Fuglstad, G., D. Simpson, F. Lindgren, and H. Rue. 2017. Constructing priors that penalize the 1216 complexity of gaussian random fields , pp. 1-33, arXiv.org,http://arxiv.org/abs/1503.00256.

1218 Gannon, B. M., and P. H. Martin. 2014. Reconstructing hurricane disturbance in a tropical 1219 montane forest landscape in the Cordillera Central, Dominican Republic: implications for 1220 vegetation patterns and dynamics. Arctic, Antarctic, and Alpine Research 46: 767-776.

1221

1222 Gelman, A. 2005. Analysis of variance: why it is more important than ever. Annals of Statistics 1223 33: 1-31.

1224 
1225 Gneiting, T., F. Balabdaoui, and A. E. Raftery. 2007. Probabilistic forecasts, calibration and 1226 sharpness. Journal of the Royal Statistical Society: Series B (Statistical Methodology) 69: 2431227268.

1228

1229 Heartsill Scalley, T. 2017. Insights on forest structure and composition from long-term research 1230 in the Luquillo Mountains. Forests 8: 204.

1231

1232 Held, L., B. Schrödle, and H. Rue. 2010. Posterior and cross-validatory predictive checks: a 1233 comparison of MCMC and INLA. Pages 91-110 in Statistical modelling and regression 1234 structures. Physica-Verlag HD.

1235

1236 Hogan, J. A., J. K. Zimmerman, J. Thompson, M. Uriarte, N. G. Swenson, R. Condit, S. Hubbell, 1237 D. J. Johnson, I F. Sun, C.-H. Chang-Yang, S.-H. Su, P. Ong, L. Rodriguez, C. C. Monoy, S. 1238 Yap, and S. J. Davies 2018. The frequency of cyclonic wind storms shapes tropical forest 1239 dynamism and functional trait dispersion. Forests 9: 404.

1240

1241 Ibanez, T., G. Keppel, C. Menkes, T. W. Gillespie, M. Lengaigne, M. Mangeas, G. Rivas-Torres, 1242 and P. Birnbaum. 2019. Globally consistent impact of tropical cyclones on the structure of 1243 tropical and subtropical forests. Journal of Ecology 107: 279-292.

1245 Jenness, J., B. Brost, and P. Beier. 2013. Land facet corridor designer: Topographic position 1246 index tools. Available at: http://corridordesign.org/downloads. 
1248 Knutson T. R., J. L. McBride, J. Chan, K. Emanuel, G. Holland, C. Landsea, I. Held, J. P.

1249 Kossin, A. K. Srivastava, and M. Sugi. 2010. Tropical cyclones and climate change. Nature

1250 Geoscience 3: 157

1251

1252 Krainski, E. T., F. Lindgren, D. Simpson, and H. Rue. 2017. The R-INLA tutorial on SPDE

1253 models. Journal of Geographical Systems. http://www. math. ntnu. no/inla/r-inla.

1254 org/tutorials/spde/spde-tutorial. pdf.

1255

1256 Lawton, R.O. 1982. Wind stress and elfin stature in a montane rain forest tree: an adaptive

1257 explanation. American Journal of Botany 69:1224-1230.

1258

1259 Lin, K. C., S. P. Hamburg, L. Wang, C. T. Duh, C. M. Huang, C. T. Chang, and T. C. Lin. 2017.

1260 Impacts of increasing typhoons on the structure and function of a subtropical forest: reflections

1261 of a changing climate. Scientific Reports 7: 4911.

1262

1263 Lindgren, F., and H. Rue. 2015. Bayesian spatial modelling with R-INLA. Journal of Statistical

1264 Software 63: 19.

1265

1266 Lindgren, F., H. Rue, and J. Lindstromm. 2011. An explicit link between Gaussian fields and

1267 Gaussian Markov random fields: The SPDE approach. Journal of the Royal Statistical Society

1268 Series B 73: 423-498.

1269 
1270 Logan, J. R., and Z. Xu. 2015. Vulnerability to hurricane damage on the US Gulf Coast since

1271 1950. Geographical Review 105: 133-155.

1272

1273 Luke, D., K. McLaren, and B. Wilson. 2016a. Modeling hurricane exposure in a Caribbean lower

1274 montane tropical wet forest: The effects of frequent, intermediate disturbances and topography

1275 on forest structural dynamics and composition. Ecosystems 19: 1178-1195.

1276

1277 Luke, D., K. McLaren, and B. Wilson. 2016b. Short-term dynamics and the effects of biotic and

1278 abiotic factors on plant physiognomic groups in a hurricane-affected lower montane tropical

1279 forest. Biotropica 48: 332-341.

1280

1281 Martins, T. G., D. Simpson, F. Lindgren, and H. Rue. 2013. Bayesian computing with INLA:

1282 new features. Computational Statistics \& Data Analysis 67: 68-83.

1283

1284 McGroddy, M., D. Lawrence, L. Schneider, J. Rogan, I. Zager, and B. Schmook. 2013. Damage

1285 patterns after Hurricane Dean in the southern Yucatán: Has human activity resulted in more

1286 resilient forests? Forest Ecology and Management 310: 812-820.

1287

1288 Mikita, T., and M. Klimánek. 2010. Topographic exposure and its practical applications. Journal 1289 of Landscape Ecology 3: 42-51.

1290 
1291 Muchoney, D.M., S. Iremonger, and R. Wright. 1994. Rapid Ecological Assessment: Blue and 1292 John Crow Mountains National Park, Jamaica. The Nature Conservancy, Arlington Virginia, 1293 USA.

1294

1295 Negrón-Juárez, R., D. B. Baker, J. Q. Chambers, G. C. Hurtt, and S. Goosem. 2014a. Multi-scale 1296 sensitivity of Landsat and MODIS to forest disturbance associated with tropical

1297 cyclones. Remote Sensing of Environment 140: 679-689.

1298

1299 Negrón-Juárez, R. I., J. Q. Chambers, G. C. Hurtt, B. Annane, S. Cocke, M. Powell, M. Stott, S.

1300 Goosem, D. J. Metcalfe and S. S. Saatchi. 2014b. Remote sensing assessment of forest

1301 disturbance across complex mountainous terrain: The pattern and severity of impacts of tropical

1302 cyclone Yasi on Australian rainforests. Remote Sensing 6: 5633-5649.

1303

1304 Pettit, L. 1990. The conditional predictive ordinate for the Normal distribution. Journal of the 1305 Royal Statistical Society, Series B 56: 3-48.

1306

1307 Pike, R.J., I. Evans, and T. Hengl. 2008. Geomorphometry: A Brief Guide. In Hengl, T. and

1308 Reuter, H. I. (eds.), Geomorphometry - Concepts, Software, Applications. Series Developments

1309 in Soil Science, Volume 33, Elsevier, 3-33.

1310

1311 R Development Core Team. 2017. R: "A Language and Environment for Statistical Computing."

1312 R Foundation for Statistical Computing, Vienna. http://www.R-project.org/. 
1314 Rossi, E., I. Granzow de la Cerda, C. D. Oliver, and D. Kulakowski. 2017. Wind effects and

1315 regeneration in broadleaf and pine stands after hurricane Felix (2007) in Northern

1316 Nicaragua. Forest Ecology and Management 400: 199-207.

1317

1318 Roxburgh, S. H., K. Shea, and J. B. Wilson. 2004. The intermediate disturbance hypothesis:

1319 patch dynamics and mechanisms of species coexistence. Ecology 85: 359-371.

1320

1321 Rue, H., and Martino, S. 2007. Approximate Bayesian inference for hierarchical Gaussian

1322 Markov random field models. Journal of Statistical Planning and Inference 137: 3177-3192.

1323

1324 Rue, H., S. Martino, and N. Chopin. 2009. Approximate Bayesian inference for latent Gaussian 1325 models using integrated nested Laplace approximations (with discussion). Journal of the Royal 1326 Statistical Society, Series B 71:319-392.

1327

1328 Rue, H., A. Riebler, S. H. Sørbye, J. B. Illian, D. P. Simpson, and F. K. Lindgren. 2017.

1329 Bayesian computing with INLA: a review. Annual Review of Statistics and its Application 4: $1330 \quad 395-421$.

1331

1332 Ruel, J. C., S. J. Mitchell, and M. Dornier. 2002. A GIS based approach to map wind exposure 1333 for windthrow hazard rating. Northern Journal of Applied Forestry 19: 183-187. 
1335 Runkle, J. R., 1985: Disturbance regimes in temperate forests. In Pickett, S. T. A., and White, P.

1336 S. (eds.), The Ecology of Natural Disturbance and Patch Dynamics. New York: Academic Press, 1337 17-34.

1338

1339 Scatena, F. N., and M. C. Larsen. 1991. Physical aspects of Hurricane Hugo in Puerto Rico.

1340 Biotropica 23: 317-323.

1341

1342 Schielzeth, H., and S. Nakagawa. 2013. Nested by design: model fitting and interpretation in a 1343 mixed model era. Methods in Ecology and Evolution 4: 14-24.

1344

1345 Shea, K., Roxburgh, S. H., and Rauschert, E. S. 2004. Moving from pattern to process:

1346 coexistence mechanisms under intermediate disturbance regimes. Ecology Letters 7: 491-508.

1347

1348 Sheil, D. 1999. Tropical forest diversity, environmental change and species augmentation: after

1349 the intermediate disturbance hypothesis. Journal of Vegetation Science 10: 851-860.

1350

1351 Sheil, D., and D. F. Burslem. 2013. Defining and defending Connell's intermediate disturbance

1352 hypothesis: a response to Fox. Trends in ecology \& evolution 28: 571-572.

1353

1354 Simpson, D., H. Rue, A. Riebler, T. G. Martins, and S. H. Sørbye. 2017. Penalising model

1355 component complexity: A principled, practical approach to constructing priors. Statistical

1356 Science 32: 1-28.

1357 
1358 Spiegelhalter, D.J., N.J. Best, B.P. Carlin, and A. Van Der Linde. 2002. Bayesian measures of

1359 model complexity and fit. Journal of the Royal Statistical Society: Series B (Statistical

1360 Methodology) 64: 583-639.

1361

1362 Tanner, E.V.J. 1977. Four montane rain forests of Jamaica: a quantitative characterization of the

1363 floristics, the soils and the foliar mineral levels, and a discussion of the interrelations. Journal of

1364 Ecology 65: 883-918.

1365

1366 Tanner, E. V. J., and P. J. Bellingham 2006. Less diverse forest is more resistant to hurricane

1367 disturbance: evidence from montane rain forests in Jamaica. Journal of Ecology 94: 1003-1010.

1368

1369 Tanner, E. V., F. Rodriguez-Sanchez, J. R. Healey, R. J. Holdaway, and P. J. Bellingham. 2014.

1370 Long-term hurricane damage effects on tropical forest tree growth and mortality. Ecology 95 :

$13712974-2983$.

1372

1373 Uriarte, M., J. Thompson, and J. K. Zimmerman. 2019. Hurricane María tripled stem breaks and

1374 doubled tree mortality relative to other major storms. Nature Communications 10: 1362.

1375

1376 Vandermeer, J., I. G. de la Cerda, D. Boucher, I. Perfecto, and J. Ruiz. 2000. Hurricane

1377 disturbance and tropical tree species diversity. Science 290: 788-791.

1378

1379 Weaver, P. L. 1986. Growth and age of Cyrilla racemiflora L. in montane forests of Puerto

1380 Rico. Interciencia 11: 221-228. 
1382 Weaver, P. L. 2002. A chronology of hurricane induced changes in Puerto Rico s lower montane 1383 rain forest. Interciencia 27: 252-258.

1384

1385 Webb, L. J. 1958. Cyclones as an ecological factor in tropical lowland rain-forest, north

1386 Queensland. Australian Journal of Botany 6: 220-228.

1387

1388 Xi, W., R. K. Peet, J. K. Decoster, and D. L. Urban. 2008. Tree damage risk factors associated 1389 with large, infrequent wind disturbances of Carolina forests. Forestry 81: 317-334.

Zheng, B. 2000. Summarizing the goodness of fit on generalized linear models for longitudinal 1392 data. Statistics in Medicine 19: 1265-1275.

Zimmerman, J. K., E. M. Everham III, R. B. Waide, D. J. Lodge, C. M. Taylor, and N. V. Brokaw. 1994. Responses of tree species to hurricane winds in subtropical wet forest in Puerto Rico: implications for tropical tree life histories. Journal of Ecology 82: 911-922. spatial-temporal ecological data analysis with R-INLA. Volume I: Using GLM and GLMM.

1400 Highland Statistics Ltd., Newburgh United Kingdom. 


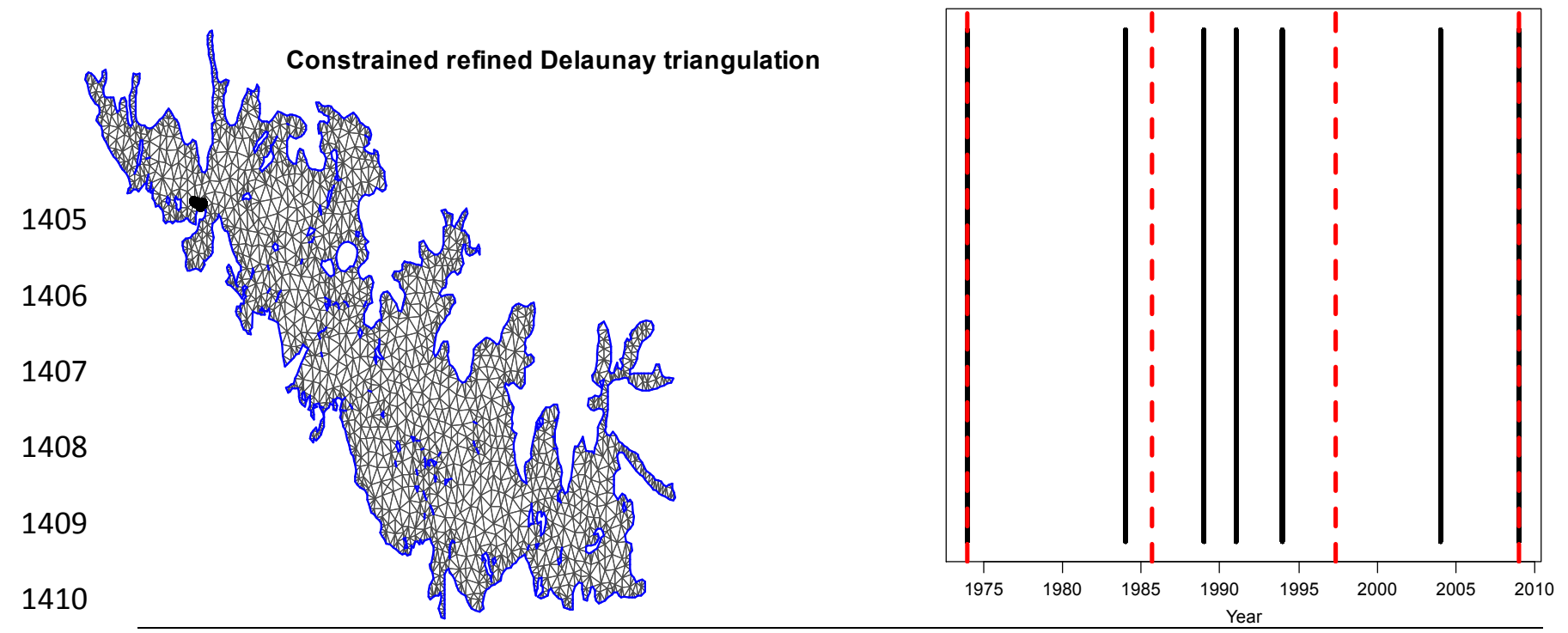

1411

1412

1413

1414

1415

1416

1417

1418
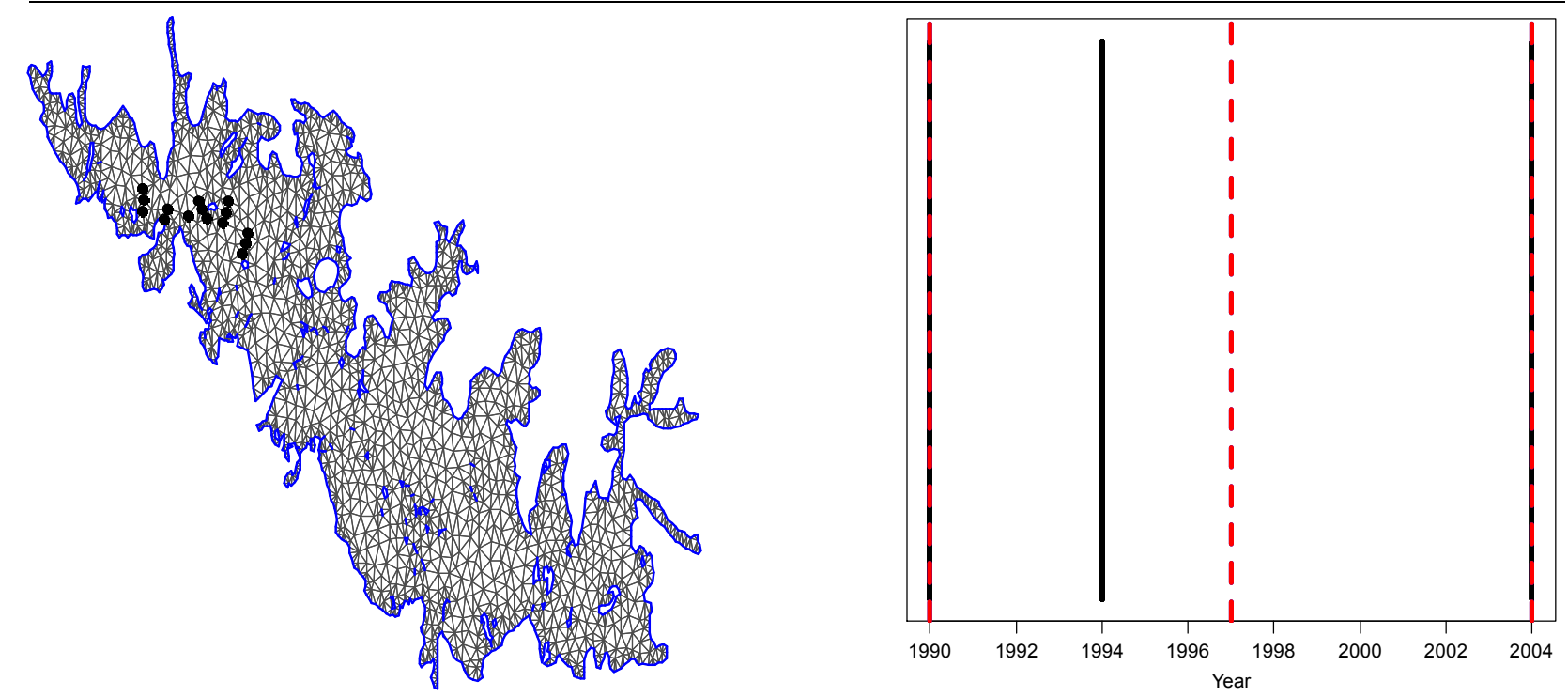

1419

1420

1421

1422

1423

1424

1425

1426

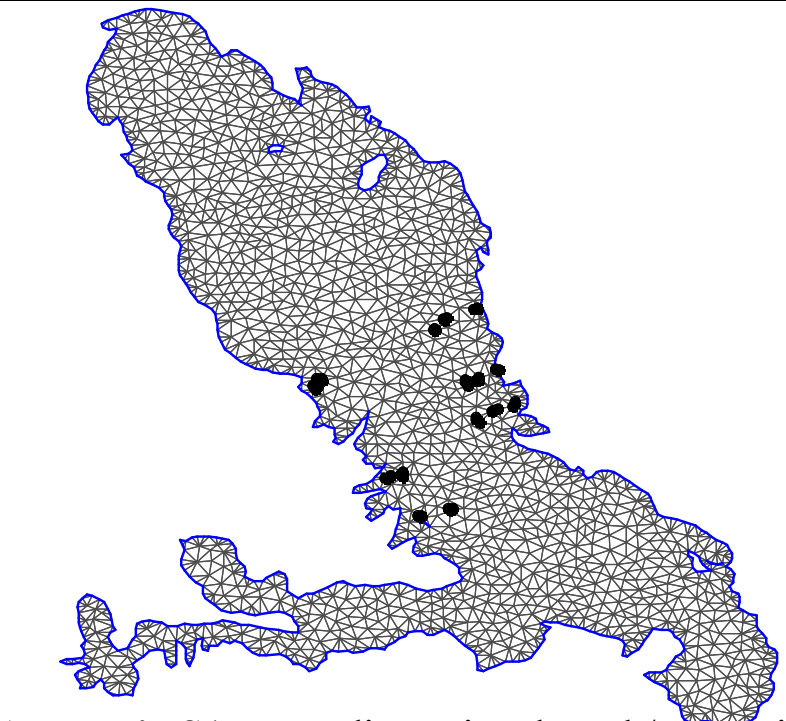

1427 Appendix S1. Two-dimensional mesh/constrained refined Delaunay triangulation used to

1428 calculate the Gaussian (Markov) random field in the SPDE approach (left) and the knots (dashed 1429 red lines) used for a one-dimensional mesh for the temporal component of the models (right) for 1430 the Blue Mountains (top: Tanner's plots; middle: Bellingham's plots). The bottom mesh is for 
1431 the John Crow Mountains (Luke et al.'s (2016)) plots. The plots are shown as black closed 1432 circles. The solid black lines are the censuses. 